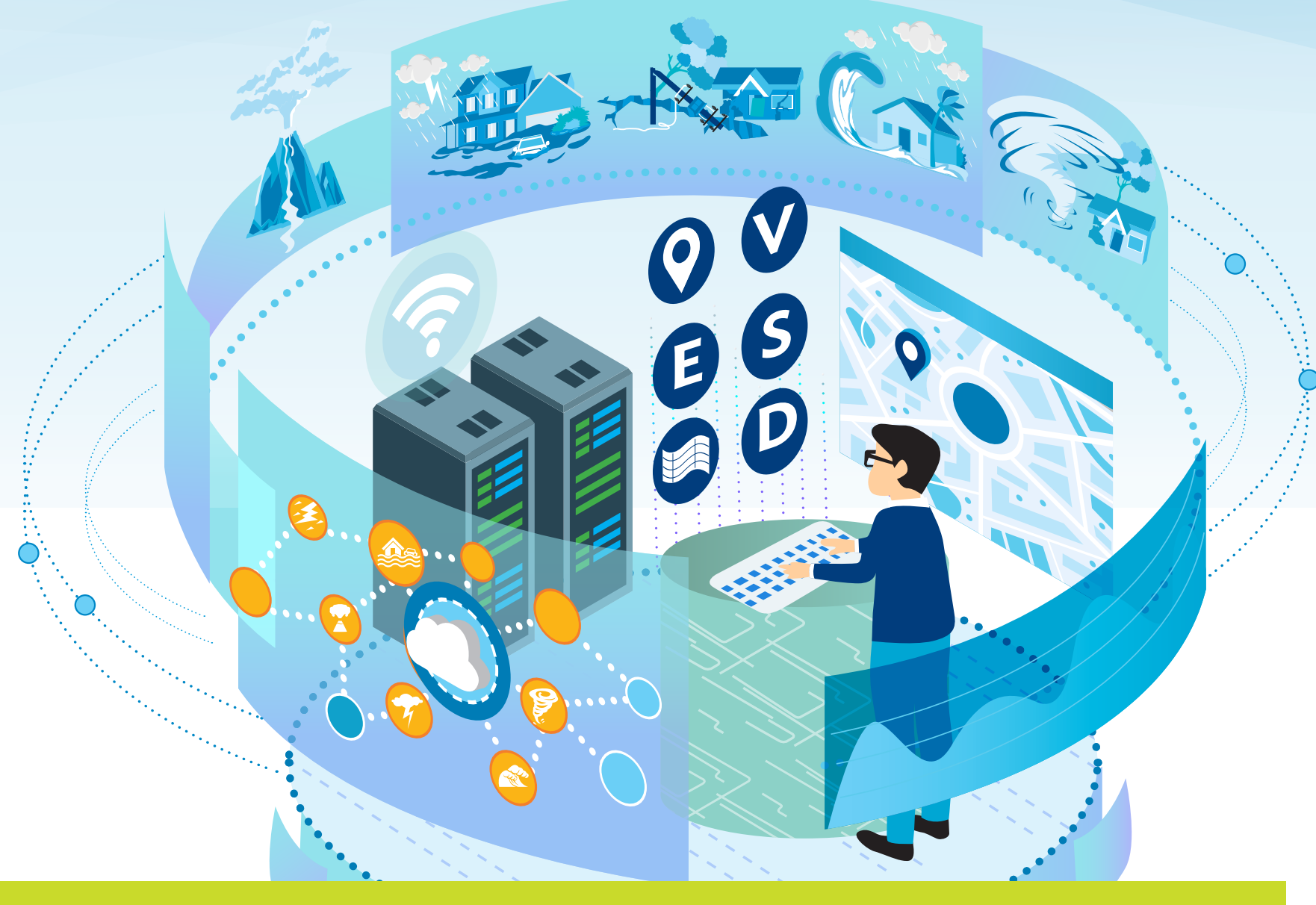

LEVERAGING TECHNOLOGY AND INNOVATION FOR

DISASTER RISK MANAGEMENT AND FINANCING

DECEMBER 2020 



\section{LEVERAGING TECHNOLOGY \\ AND INNOVATION FOR \\ DISASTER RISK MANAGEMENT \\ AND FINANCING}

DECEMBER 2020

Co-publication of the Asian Development Bank and OECD. 
Creative Commons Attribution Non-Commercial No Derivatives 3.0 IGO license (CC BY-NC-ND 3.0 IGO)

(C) 2020 Asian Development Bank (ADB) and Organisation for Economic Co-operation and Development (OECD) Some rights reserved. Published in 2020.

Please cite this publication as:

ADB and OECD. 2020. Leveraging Technology and Innovation for Disaster Risk Management and Financing. Manila/Paris.

ISBN 978-92-9262-595-5 (print), 978-92-9262-596-2 (electronic), 978-92-9262-597-9 (ebook)

Publication Stock No. TCS200393-2

DOI: http://dx.doi.org/10.22617/TCS200393-2

This document was prepared by the Asian Development Bank and the Organisation for Economic Co-operation and Development as an input for discussions in the APEC Finance Ministers' Process. The views expressed and arguments employed in this publication are those of the authors and do not necessarily reflect the views and policies of the Asian Development Bank (ADB), its Board of Governors or the governments they represent, or of OECD member countries.

$A D B$ and $O E C D$ do not guarantee the accuracy of the data included in this publication and accept no responsibility for any consequence of their use. The mention of specific companies or products of manufacturers does not imply that they are endorsed or recommended by ADB or OECD in preference to others of a similar nature that are not mentioned.

By making any designation of or reference to a particular territory or geographic area, or by using the term "country" in this document, neither ADB nor OECD intends to make any judgments as to the legal or other status of any territory or area. This document and any map included herein are without prejudice to the status of or sovereignty over any territory, to the delimitation of international frontiers and boundaries and to the name of any territory, city or area.

This work is available under the Creative Commons Attribution Non-Commercial No Derivatives 3.0 IGO license (CC BY-NC-ND 3.0 IGO) https://creativecommons.org/licenses/by-nc-nd/3.0/igo/. By using the content of this publication, you agree to be bound by the terms of this license. The use of this work, whether digital or print, is governed by the Terms and Conditions to be found at https://www.adb.org/terms-use and http://www.oecd.org/termsandconditions/.

This CC license does not apply to non-ADB or OECD copyright materials in this publication. If the material is attributed to another source, please contact the copyright owner or publisher of that source for permission to reproduce it. $A D B$ or OECD cannot be held liable for any claims that arise as a result of your use of the material.

Please contact pubsmarketing@adb.org if you have questions or comments with respect to content, or if you wish to obtain copyright permission for your intended use that does not fall within the license terms, or for permission to use the ADB logo.

Corrigenda to ADB publications may be found at http://www.adb.org/publications/corrigenda.

Notes:

In this publication, “\$” refers to United States dollars.

ADB recognizes "China" as the People's Republic of China, "Korea” as the Republic of Korea, and "Vietnam" as Viet Nam.

Cover design by Jasper Lauzon. 


\section{Contents}

Figures and Boxes $\quad$ iv

Foreword $\quad$ v

Acknowledgments viii

Executive Summary $\quad x$

1 Context 1

APEC economies are highly exposed to disaster and climate risks

Vulnerability to natural hazards is likely to increase across APEC 2

Limited progress in building financial resilience 4

Building resilience against disaster and climate risks 5

The potential contribution of technology and innovation 6

2 Emerging Technologies and Innovation 8

The impact of digital transformation on data access, processing, and transmission 8

Emerging technologies and innovations for disaster risk management and financing 9

3 The Contribution of Emerging Technologies and Innovation to Risk and Impact Assessment 13

4 Applications of Emerging Technologies to Risk Reduction and Preparedness 20

More effective land use and spatial planning 20

Better targeted investment in risk reduction 21

Improved preparedness 22

More efficient disaster response and/or recovery 26

5 Applications of Emerging Technologies to the Financial Management of Disaster and Climate Risks 28

Enhancing the availability and affordability of indemnity insurance 29

Parametric insurance solutions 36

Managing public finance response to disaster risks 37

6 Leveraging Emerging Technologies and Innovation: Challenges and Recommendations 39

Building an enabling environment for the application of emerging technologies and innovations 40

Opportunities for international cooperation 48

References 49 


\section{Figures and Boxes}

\section{Figures}

1.1 Economic Losses by Income Level, 2000-2019 2

1.2 Economic Losses from Natural Catastrophes in APEC Economies by Peril, 2000-2019 3

1.3 INFORM Hazard, Exposure, and Vulnerability Scores 4

1.4 Share of Economic Losses Insured by Income Level, 2010-2019 5

1.5 Reducing the Impact of Disaster and Climate Risk 6

2.1 Applications of Emerging Technologies and Innovation to Disaster Risk Management and Financing 12

3.1 Applying Emerging Technologies to Risk Assessment 17

3.2 Applying Emerging Technologies to Damage Assessment 19

5.1 Improving the Affordability of Insurance Coverage 35

Boxes

4.1 Assessing Rainy Season Flood Risk in the People's Republic of China 25

5.1 Building Financial Resilience to Disaster Risks: Guidance for Policymakers 28

5.2 Enhancing Availability of Insurance Coverage for Wildfire Risk 31

6.1 Addressing Prudential and Market Conduct Risks in the Application of Emerging Technologies 46

6.2 Encouraging Technology Adoption 47 


\section{Foreword}

Enhancing social, economic, and financial resilience in the face of increasing disaster and climate risk will be one of the most enduring challenges for the Asia-Pacific Economic Cooperation (APEC) finance ministers in coming years.

Digital technologies are transforming our economies and creating opportunities to build resilience and improve efficient and effective delivery of outcomes across almost every policy area-including disaster risk management. Internet access, smartphones, connected devices, cloud computing, artificial intelligence, and other innovations will likewise transform the way we measure and monitor disaster risk and impacts and provide more comprehensive, accurate, and timely risk analysis. These developments are also changing how insurance is being designed, underwritten, distributed, and settled. Indeed, they are offering huge opportunity to broaden access to this financial tool, distribute some of the financial burden of disaster and climate risk to insurance and capital markets, and assist vulnerable communities and small businesses.

The coronavirus disease (COVID-19) pandemic vividly illustrates the enormous hardships that can result from a crisis and underscores the need to prepare for them.

This report is a joint effort by the Asian Development Bank (ADB) and the Organisation for Economic Cooperation and Development (OECD) to analyze those trends and to provide policymakers and stakeholders in the APEC region and beyond with suggestions for meeting those challenges in the coming years. While much of the development and discussion of this report occurred before the pandemic, the current crisis clearly highlights the importance of embracing new technologies and the need for governments to undertake advance risk planning. COVID-19 has forced governments and businesses around the world to rethink stakeholder engagement and service delivery. Many have embraced new online distribution and communication processes-out of necessity at first, and now because of the efficiencies achieved. COVID-19 will likely accelerate the penetration of digital technologies and could foster innovation and, in turn, allow the adoption of digital and innovative applications to strengthen disaster resilience.

To capitalize on emerging technological opportunities, therefore, APEC members need a policy environment that rewards innovation and a regulatory environment that enhances it. Yet, creating one is no easy task. Technological development and reliance create a host of issues across many policy areas, from consumer protection and privacy to security and safety to financial sector supervision and oversight. It also creates new risks that-if poorly managed-could entrench biases and existing inequalities.

APEC members have much to gain from addressing these challenges together-sharing their expertise and developing an approach that allows those that wish to apply emerging technologies and innovations to benefit from the economies of scale of APEC-wide implementation. COVID-19 is also demonstrating that regional cooperation is critical to containing such a pandemic and crucial in securing a sustainable and resilient recovery. 
In the same vein, regional cooperation will remain important to strengthening disaster resilience in APEC economies moving forward.

$A D B$ and the OECD look forward to continuing their support to the APEC Finance Ministers' Process for strengthening disaster risk resilience.

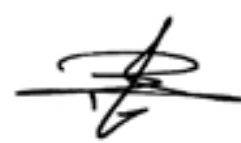

Yasuyuki Sawada

Chief Economist and Director General

Economic Research and Regional

Cooperation Department

Asian Development Bank

\section{河野正道佻}

Masamichi Kono

Deputy Secretary-General

Organisation for Economic Co-operation

and Development 


\section{Foreword}

The Asia-Pacific Economic Cooperation (APEC) region, the world's most exposed region to disasters and climate risks, accounted for more than $40 \%$ of all disaster victims and over $80 \%$ of economic losses from 2000 to 2019. Indeed, APEC economies faced 8 of 10 costliest earthquakes and 7 of 10 costliest floods between 2000 and 2018 .

As these risks grow, so will the need for boosting social, economic, and financial resilience in the coming years. Likewise, the potential for significant positive impact of effective action on lives and well-being will be necessary.

Recognizing the challenges ahead, in 2015 APEC Finance Ministers prioritized the building of financial resilience as a pillar of the Cebu Action Plan. The plan highlights the need for disaster risk financing and insurance mechanisms and strategies that enable APEC economies exposed to climate hazards to increase their financial response to disasters and reduce their fiscal burdens. Specific initiatives and deliverables of the plan relate to enhancing financial resilience against disaster risks such as through promoting disaster insurance schemes, deepening insurance penetration, and developing regional risk sharing measures. The dedicated Working Group on Regional Disaster Risk Financing Solutions for APEC Economies was established at the time and has met under every APEC Host year since.

To aid economies in this effort and as part of the working group's commitments, APEC Finance Ministers in their 2019 Joint Ministerial Statement asked the Asian Development Bank (ADB) and the Organisation for Economic Co-operation and Development (OECD) to assess the implications of technology and innovation for disaster risk management and financing. The report thus examines the potential for emerging technologies and innovation to improve the management of disaster and climate risks - and the availability and affordability of financial protection tools-based on practical examples of the implementation of technology and innovation from the APEC region and across the world.

This important ADB-OECD report could not come at a better time for the APEC region. The unfolding coronavirus disease (COVID-19) pandemic demonstrates how quickly crises can emerge globally, with painful humanitarian and economic consequences, underpinning the need to strengthen disaster resilience. The pandemic will also likely accelerate penetration of digital technology and lead to an acceleration of innovation. This in turn could provide opportunities for the adaptation of digital and innovative applications to strengthen disaster resilience.

We are confident that this report beneficially contributes to APEC economies' efforts to enhance financial resilience against emerging disaster risks.



Undersecretary, Department of FinanceInternational Finance Group

Government of the Philippines

Co-Chair Working Group on Regional Disaster Risk Financing Solutions for APEC Economies



Takaya Kishi

Deputy Vice-Minister of Finance for International Affairs

Government of Japan

Co-Chair Working Group on Regional Disaster Risk

Financing Solutions for APEC Economies 


\section{Acknowledgments}

This report was prepared jointly by the Asian Development Bank (ADB), Regional Cooperation and Integration Division (ERCl) of the Economic Research and Regional Cooperation Department, and the Directorate for Financial and Enterprise Affairs (DAF) of the Organisation for Economic Co-operation and Development (OECD) under the overall supervision of Cyn-Young Park, Director ERCl, and Mamiko Yokoi-Arai, Head of Insurance, DAF. The ADB Technical Assistance initiative 9537-Strengthening Regional Cooperation and Integration Knowledge Partnerships and Research Network in Asia and the Pacific-supported this project.

The preparations of this report were led by Leigh Wolfrom (Policy Analyst, DAF, OECD) and Peter Rosenkranz (Economist, $\mathrm{ERCl}, \mathrm{ADB}$ ).

Background research and analysis has been prepared by Josefina Bello, Benjamin Crick, Louise Kessler, and Oliver Walker from Vivid Economics with inputs from Teresa M. Deubelli, Wei Liu, and Reinhard Mechler from the International Institute for Applied Systems Analysis (IIASA) and Swenja Surminski from the London School of Economics.

The report greatly benefited from support of ADB's Sustainable Development and Climate Change Department, with inputs provided by Arup Chatterjee (Principal Financial Sector Specialist, Finance Sector Group [SDSCFIN]), Thomas Kessler (Principal Financial Sector Specialist [Disaster Insurance], SDSC-FIN), Charlotte Benson (Principal Disaster Risk Management Specialist, Climate Change and Disaster Risk Management Division), and Paolo Manunta (Senior Infrastructure Specialist [Earth Observation], Digital Technology for Development Unit).

Helpful comments received from Rolando Avendano (Economist, ERCI, ADB), Charles Baubion (Advisor, Public Governance Directorate, OECD), Matthias Bachmann (Advisor, Sherpa Office and Global Governance Unit, OECD) and Julien Trehet (Advisor, Sherpa Office and Global Governance Unit, OECD) are gratefully acknowledged.

It has further benefited from inputs and comments provided by the Asia-Pacific Economic Cooperation (APEC) member economies, including members of the Working Group on Regional Disaster Risk Financing and Insurance Solutions for APEC Economies as well as from the OECD's Insurance Private Pensions Committee and High-Level Advisory Board on the Financial Management of Large-Scale Catastrophes.

The report team is also grateful for the helpful feedback provided by participants of the following events: the ADB-OECD Inception Workshop at the ADB Headquarters Manila (Philippines) in June 2019; the APEC Finance and Central Bank Deputies' Meeting and APEC Seminar on Disaster Risk Finance: Enhancing Financial Risk Management Against Disasters (co-organized by the Ministry of Finance of Chile and the World Bank Group) in Santiago (Chile) in October 2019; the ADB-OECD Policy Dialogue on Leveraging Technology and Innovation for Disaster Risk Management and Financing at the 3rd Asia Finance Forum: The Future of Inclusive Finance at the ADB headquarters; and the Webinar of the Working Group on Regional Disaster Risk Financing and Insurance 
Solutions for APEC Economies in September 2020. An earlier version of this report was submitted to APEC Finance Ministers in September 2020.

Peter Rosenkranz and Paulo Rodelio Halili (Senior Economics Officer, ADB) coordinated the production of this report.

Eric Van Zant edited the manuscript, Jasper Lauzon created the cover design, and Jennifer Flint implemented the typesetting and layout. Joel Pinaroc proofread the report, while Ma. Cecilia Abellar handled the page proof checking, and Erickson Mercado provided additional illustrations. The Printing Services Unit of ADB's Office of Administrative Services and the Publishing Team of the Department of Communications supported printing and publishing. 


\section{Executive Summary}

The Asia-Pacific Economic Cooperation (APEC) region is highly exposed to disaster and climate risks, accounting for more than $80 \%$ of global economic losses from disaster events in the last 20 years. The destruction and disruption that usually follow disaster events pose an important challenge to economic development and can perpetuate vulnerability. Despite substantial investment in reducing risk across the region, economic losses from disaster events continue to increase at a much faster rate than gross domestic product, implying that the relative economic burden is increasing over time. Efforts to enhance the reach of insurance and other financial protection tools have not significantly reduced the share of economic losses borne by households, businesses, and governments, which often lack the capacity to absorb these impacts. A changing climate as well as continued population growth and asset accumulation in areas exposed to disaster and climate risks is expected to exacerbate these challenges - with particular implications for vulnerable groups with limited economic resources.

Enhancing resilience in the face of increasing natural hazards, exposure, and vulnerability will require investments in reducing the economic, social, and financial impacts of disasters by improving risk and impact assessment and leveraging those improvements to invest in risk reduction, preparedness, and response. APEC finance ministers have long recognized the need to build financial resilience to disaster risks and have included this objective in their work for a number of years. The Cebu Action Plan, approved by APEC finance ministers in 2015, aims to enhance financial resilience against economic shocks, including by "developing innovative disaster risk financing and insurance mechanisms (including micro-insurance) to enable APEC economies exposed to natural hazards to increase their financial response to disasters and reduce their fiscal burden" (APEC 2015). Referenced by APEC finance ministers in their 2019 Joint Ministerial Statement, this report aims to contribute to this objective by supporting efforts to reduce underlying risk and develop tools to manage the financial consequences.

The ongoing digital transformation of economies offers opportunities to improve the management of disaster and climate risks and enhance the availability and affordability of financial protection tools, such as insurance. This report examines the potential contribution of emerging technologies and innovations to improving understanding and management of disaster risk and impacts and broadening the adoption of financial protection mechanisms. It focuses specifically on (i) developments in access to data through earth observation technology, street-level imagery, connected devices and volunteered geographical information; (ii) improvements in the capacity to process and analyze this data through cloud computing platforms and big data analytical techniques, such as artificial intelligence; and (iii) increased capacity to transmit risk and risk management information as a result of the proliferation of internet and mobile access and continued improvements in broadband and data speeds.

Evidence from various economies around the world suggests that these technologies and innovations are contributing to a more comprehensive, accurate, and timely assessment of disaster risk and impacts, more effective spatial planning, risk reduction investment and preparedness, and (in most cases) more inclusive risk transfer arrangements. The reduced cost of acquiring hazard exposure and vulnerability data through earth observation technologies, street-level imagery, connected devices, and volunteered geographic information provides significant opportunities to broaden the coverage of risk and impact information. The ability to access the 
technologies necessary to analyze and process the increasing amounts of available data has greatly improved with the proliferation of the necessary data analytical tools and technical skills.

However, leveraging the contribution of these emerging technologies and innovations will require investments by APEC governments in creating an enabling environment:

- Resilient communications infrastructure: Many emerging technologies rely on fast and reliable access to the internet.

- Technical skills: Big data analytical techniques require high levels of expertise that may not always be sufficiently available in all APEC economies.

- Access to data and analytical technologies: Achieving broad coverage through earth observation and connected cameras or sensors can be costly in economies with large landmasses and/or dispersed populations and may be constrained by regulatory impediments in policy areas such as privacy protection and air transport safety.

- Insurance regulatory constraints: The use of emerging technologies and innovation in insurance underwriting, exposure management, distribution and claims settlement may be somewhat constrained by insurance regulatory requirements in many APEC economies.

- User awareness, acceptance, and trust: The benefits of applying emerging technologies and innovations will only be leveraged if there is broad awareness, acceptance, and trust in the use of these technologies.

The synergies across emerging technologies and innovations (e.g., more high quality data leads to better trained algorithms) calls for a strategic approach to integrating these tools into disaster risk management and financing.

APEC can provide a critical forum for sharing experiences on how to build an environment that enables the integration of emerging technologies and innovations into disaster risk management and financing. This would ultimately increase the financial resilience of the region in the face of increasing disaster and climate risks. Opportunities exist to further leverage international and regional cooperation initiatives, such as the Global Financial Innovation Network and APEC's Cross-Border Privacy Rules system, to support the integration of emerging technologies and innovations.

In the context of the coronavirus disease (COVID-19) crisis, and the resulting strain on public finances and household income in APEC economies, this agenda has even greater relevance. Many of the emerging technologies and innovations discussed in this report also have the potential to support preparedness and response to pandemic risk. 



\section{Context}

\section{APEC economies are highly exposed to disaster and climate risks}

Disaster and climate events have had significant economic and social impact on the AsiaPacific Economic Cooperation (APEC) economies, leading to many casualties, destroyed buildings and infrastructure, disrupted basic services, and mass displacements. Between 2000 and 2019, APEC economies faced approximately $\$ 2.7$ trillion in economic losses and over 480,000 fatalities as a result of significant natural hazard events, accounting for more than $40 \%$ of all victims and over $80 \%$ of economic losses reported globally. APEC economies faced 8 of the 10 costliest earthquakes between 2000 and 2018 and 7 of the 10 costliest floods. In some economies, cumulative economic losses between 2000 and 2019 were equivalent to 10\% or more of 2019 gross domestic product (GDP) (including in Chile, New Zealand, the Philippines, and Thailand).

Disaster and climate risks constitute one of the most significant threats to socioeconomic development and large disaster events have been found to lead to significant sustained declines in productivity (World Bank 2020a). Disasters often affect the poorest segments of the population disproportionately, those without savings or wealth to recover, destroying their homes and livelihoods (ADB 2019a). Poorer countries and communities are thus particularly vulnerable. While financial exposure to disasters is greatest in developed countries due to the higher value of productive assets in these countries (Figure 1.1), poorer countries' more limited capacity to bear and recover from disaster impacts often increases economic and social vulnerability. One recent analysis suggests that damages and losses resulting from natural hazards can undermine economic growth and poverty reduction in the region (UNESCAP 2019). Disaster risk can cause and sustain poverty, with direct disaster impacts putting 26 million people into poverty every year (Hallegatte et al. 2016). By jeopardizing economic development, disasters can perpetuate vulnerability, increasing the impacts of future disasters.

The study specifically examined the costs and benefits of adopting the 2018 International Residential Code and International Building Code developed by the International Code Council against construction based on the building codes in place in the 1990s in the United States (NIBS 2019). 
Figure 1.1: Economic Losses by Income Level, 2000-2019

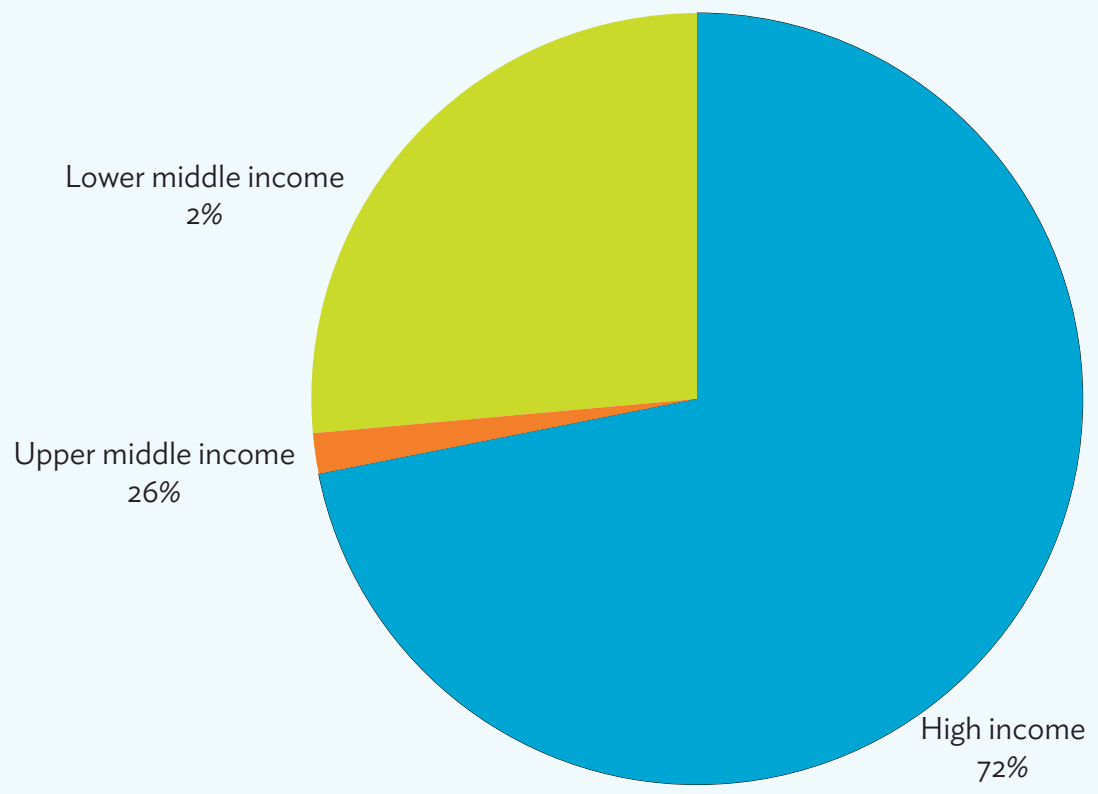

Sources: OECD calculations based on Swiss Re sigma (2020) and the World Bank's lending groups classification (World Bank 2020b).

\section{Vulnerability to natural hazards is likely to increase across APEC}

While annual economic losses vary significantly, economic losses resulting from natural catastrophes have trended upward since 2000. The growth in economic losses has outpaced growth in GDP across the APEC region, implying that the relative economic burden of disasters has grown over time (Figure 1.2).

According to some projections, disaster losses in the Asia and Pacific region could reach up to $\$ 160$ billion per year by 2030 (UNESCAP 2018) (from $\$ 136$ billion per year between 2000 and 2019). The INFORM index, which integrates information on historical disasters, forward-looking probabilistic assessments of disaster risk and indicators of vulnerability and coping capacity, indicates that, on average, APEC member economies face a "hazard and exposure" index of 4.9 out of 10 , compared to a world average of 3.7. Within APEC, lower and upper middle-income economies have higher scores on hazard and exposure (3.4 versus 6.1), vulnerability (3.5 versus 1.6), and lack of coping capacity (4.4 versus 2.1 ) than highincome APEC economies (Figure 1.3).

Economic and social trends-along with the risks related to a changing climate-are expected to increase disaster risks across the APEC region:

- Continued economic development is expected to lead to an increase in the stock of physical assets (buildings and infrastructure) exposed to disaster risks, particularly 
in developing APEC economies where growth forecasts have generally been higher than the global average. ${ }^{2}$

- Increasing urbanization and land-use change, often with accumulation in coastal regions facing storm surge hazards and other vulnerable areas, are expected to increase the number of people and assets exposed to natural hazards. More than $70 \%$ of the population of APEC economies is expected to reside in urban areas by 2030, compared to 65\% in 2018 and 60\% expected for the whole world in 2030 (United Nations, Department of Economic and Social Affairs 2018).

- A changing climate is expected to increase the likelihood of a host of climaterelated catastrophes, including windstorms, pluvial and coastal flooding, droughts, and wildfires (IPCC 2012).

Figure 1.2: Economic Losses from Natural Catastrophes in APEC Economies by Peril, 2000-2019

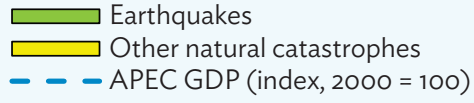

Economic losses

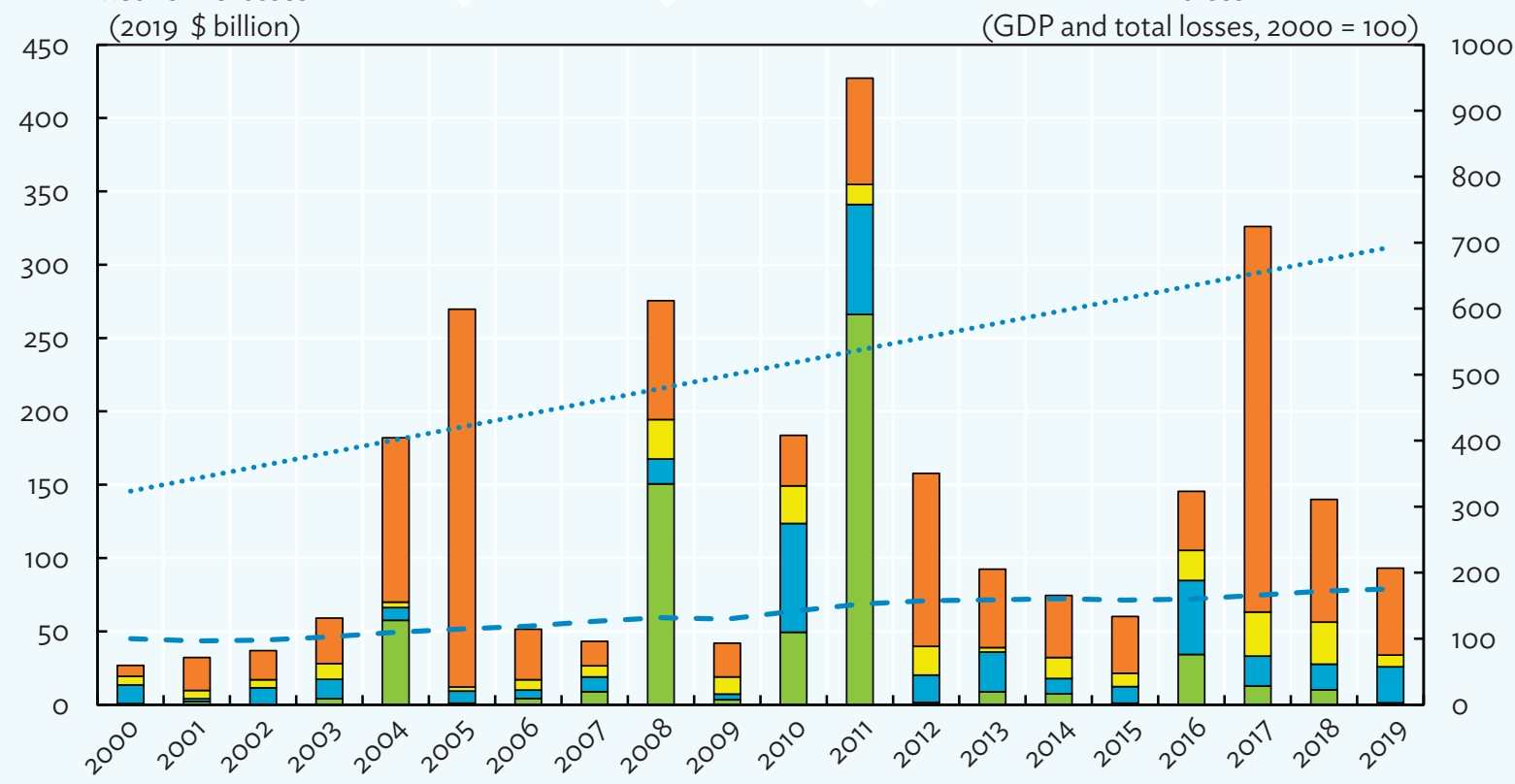

APEC $=$ Asia-Pacific Economic Cooperation, GDP = gross domestic product

Sources: OECD calculations based on Swiss Re sigma (2020); IMF. World Economic Outlook Database (accessed 18 November 2019).

2 There are a number of factors that impact the demand for-and supply of-insurance coverage. Insurance demand (and therefore, willingness-to-pay) may be lower where there are low levels of financial literacy or risk awareness, lack of trust in insurance companies/products or the existence of alternative sources of funding for post-disaster recovery and reconstruction. The supply of insurance may be low if the level of risk is high, there is a lack of data to assess risk or operational and distributional costs are high. For more information on demand and supply challenges, see (OECD 2018c, OECD 2016, Surminski and Vivid Economics 2018). 
Figure 1.3: INFORM Hazard, Exposure, and Vulnerability Scores

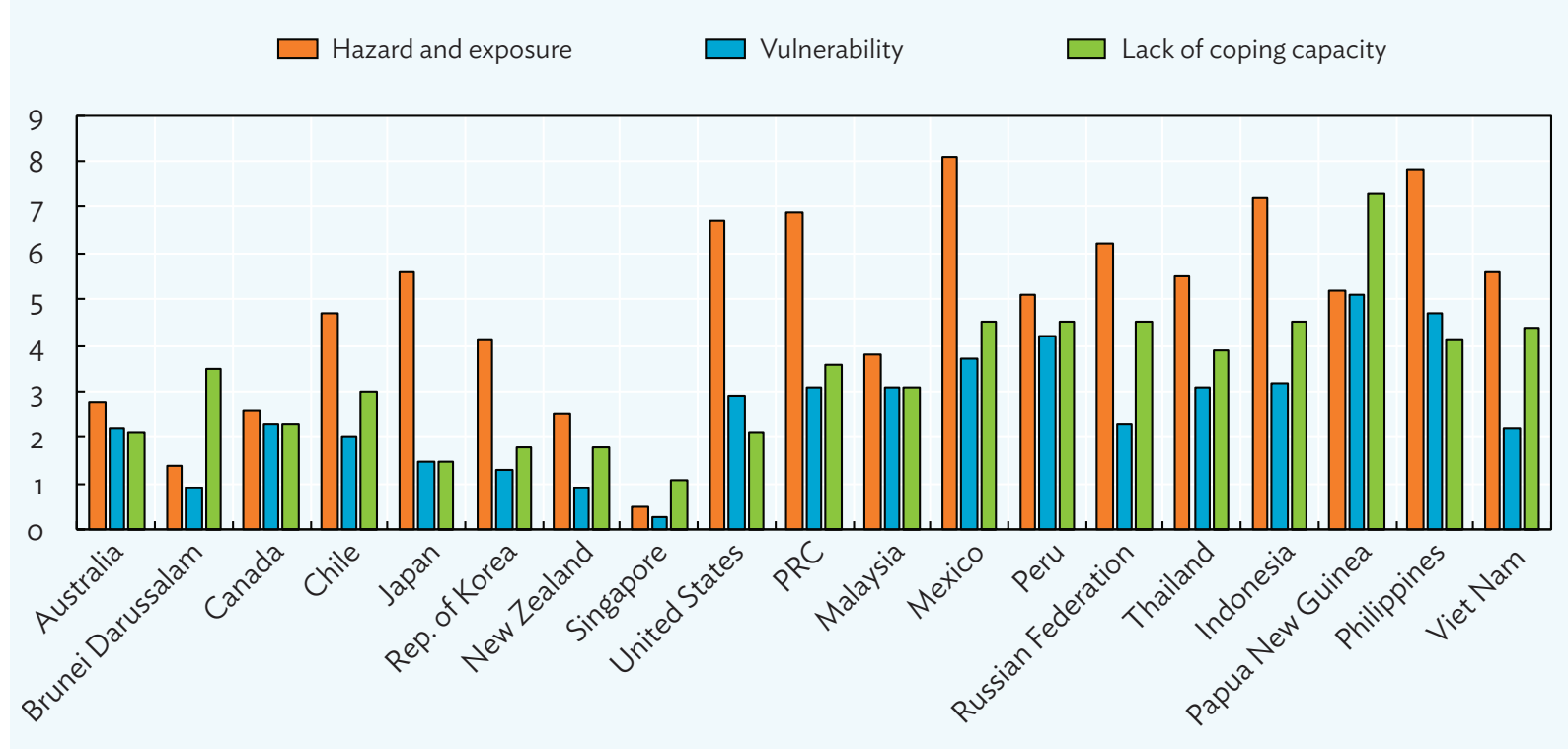

PRC = People's Republic of China.

Notes: The hazards and exposure score reflects the probability of physical exposure associated with specific hazards, incorporating data from United Nations International Strategy for Disaster Reduction Global Assessment Report, Global Seismic Hazard Map, Agricultural Stress Index (Food and Agriculture Organization of the United Nations), United States Geological Survey (PAGER), Centre for Research on the Epidemiology of Disasters, and National Oceanic and Atmospheric Administration. The vulnerability score incorporates data on a variety of vulnerability indicators, including inequality, food security, health conditions, and aid dependency (among others). The lack of coping capacity score incorporates data on disaster risk reduction practices, governance, physical infrastructure, communications, and access to health care.

Source: European Commission Joint Research Centre. INFORM Global Risk Index 2020. European Commission, https://drmkc.jrc. ec.europa.eu/inform-index/Results/Global.

\section{Limited progress in building financial resilience}

A significant share of disaster and climate-related losses are borne by the affected households, businesses and governments. Progress has been limited in increasing the contribution of insurance to absorbing the losses from catastrophes, particularly in middle-income APEC economies (Figure 1.4). In high-income APEC economies, the share of losses covered by insurance for 2016-2019 was just over 50\%, up from 40\% for 2010-2013. In middle-income APEC economies, the share of losses covered by insurance between 2016 and 2019 was actually lower than for 2010-2013 (6\% versus 9\%). ${ }^{3}$

3 In APEC economies classified as lower middle income in 2020 (Papua New Guinea, the Philippines, and Viet Nam), the share of economic losses insured increased to close to 9\% in 2016-2019 relative to less than 4\% between 2010 and 2013. No APEC economies are classified as low-income. 
Figure 1.4: Share of Economic Losses Insured by Income Level, 2010-2019

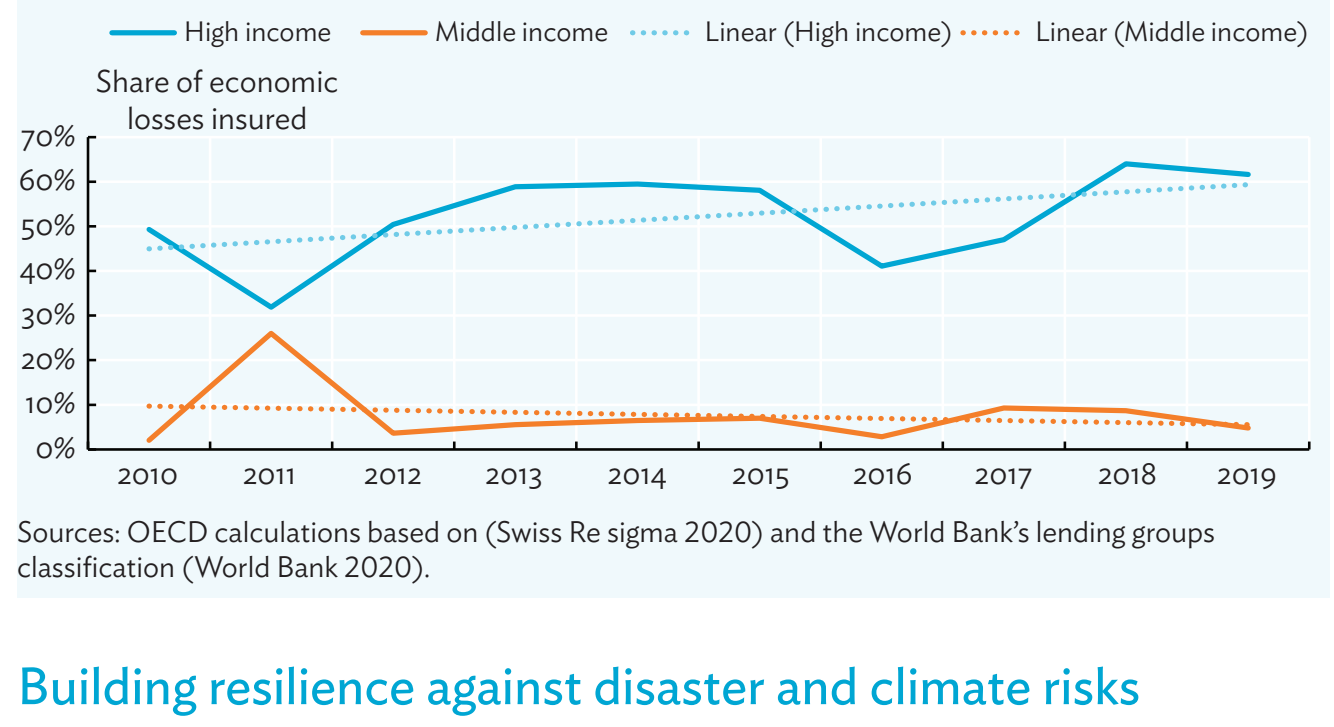

Enhancing resilience to increasing hazards, exposure, and vulnerability will require investments in reducing the economic, social, and financial impacts of disasters by improving risk and impact assessment and leveraging those improvements to invest in risk reduction, preparedness, and response (Figure 1.5).

A comprehensive understanding of hazard, exposure, vulnerability, and impact provides a sound basis for taking disaster risk management decisions that will ultimately reduce the impacts of disasters when they occur, including decisions on:

- Spatial and land-use planning, which plays a significant role in defining future exposure, particularly in urban areas where rapid unmanaged urbanization is a significant factor in increasing the vulnerability of urban populations, especially the urban poor.

- Prioritization of investments in structural and nonstructural risk mitigation measures (including the development and updating of building codes) to protect vulnerable communities, particularly where communities developed before the level of risk was well-known or where the level of risk has increased as a result of changing hazard characteristics and/or land-use.

- Measures to improve preparedness, including through more effective early warning systems that can greatly reduce vulnerability.

- Organizing emergency response, including the delivery of needed supplies, disbursement of targeted financial assistance, and the prioritization and funding for recovery and reconstruction over the medium-to-long term. 
Figure 1.5: Reducing the Impact of Disaster and Climate Risk

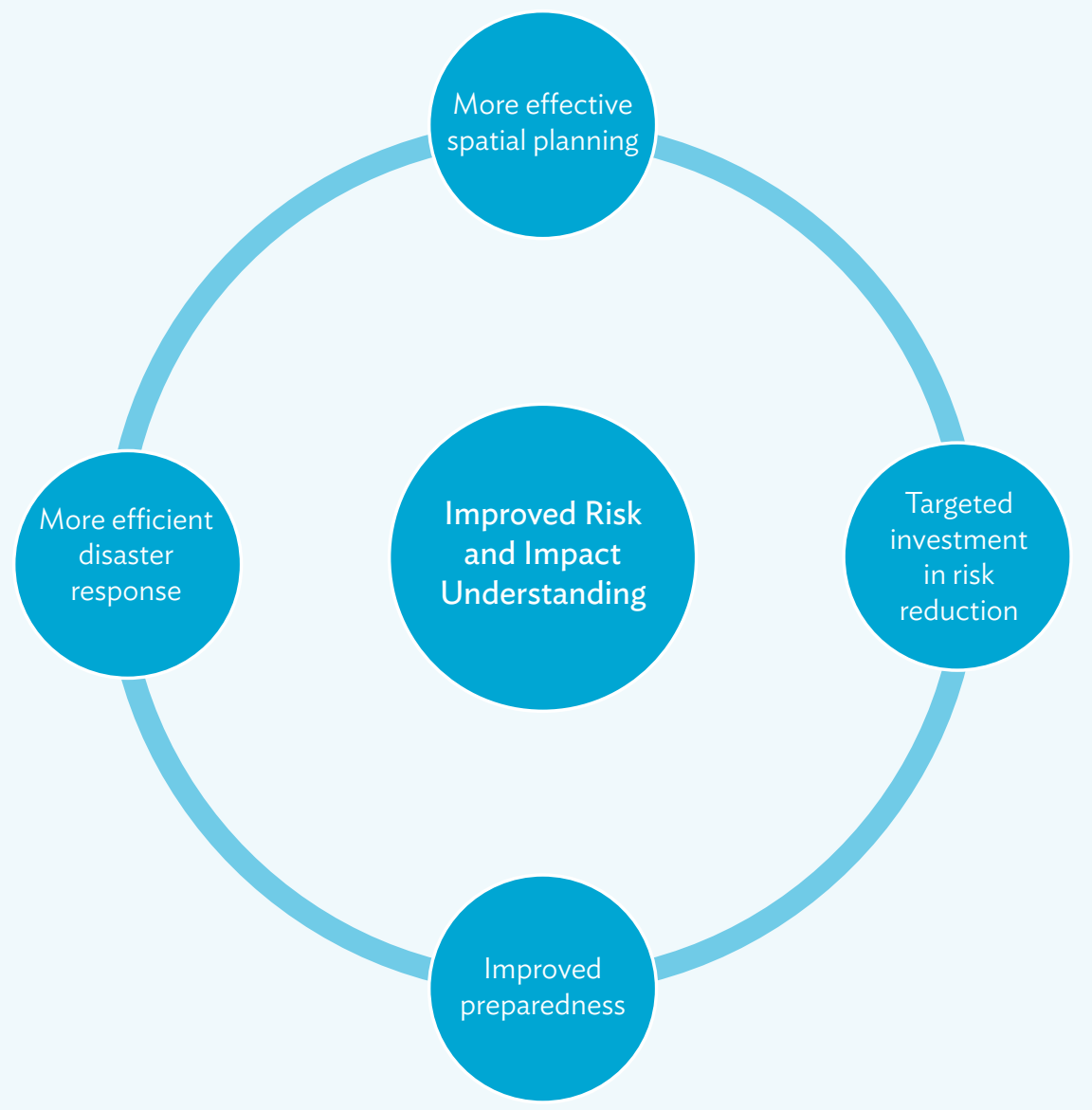

Source: OECD.

Better understanding of disaster and climate risk is also the basis for building financial resilience. Sound understanding of these risks is critical for underwriting insurance and for the proper management of the exposure to public finances created by disaster and climate risk. Financial protection tools, such as insurance, can provide households, businesses, and governments with funding to recover and rebuild after a disaster event and should reduce the overall impact of the event by supporting quicker recovery and lowering the burden on government finances. However, as noted above, in many APEC economies, insurance is making only a minimal contribution to protecting against the financial impacts of disasters.

\section{The potential contribution of technology and innovation}

Technological developments and innovation offer opportunities to improve the management of disaster and climate risks (before, during, and after disasters) and enhance the availability and affordability of financial protection tools, such as insurance. New and emerging 
technologies and innovations for data collection (e.g., earth observation), data processing (e.g., artificial intelligence) and data transmission (e.g., social networks) can be applied to improving risk assessment, reducing vulnerability, and building financial resilience. Evidence from various economies around the world suggests that these technologies and innovations are contributing to improved risk awareness, more effective planning and preparedness, and more inclusive risk transfer arrangements.

This report examines the potential for emerging technologies and innovation to improve the management of disaster and climate risks. ${ }^{4}$ It identifies practical examples of the implementation of technology and innovation from across the world and offers guidance and recommendations on how APEC finance ministers can further leverage this potential to enhance financial resilience to disaster risk across the region.

4 The report does not consider in detail various disaster risk reduction technologies that can improve the resilience of specific assets. 


\section{Emerging Technologies and Innovation}

\section{The impact of digital transformation on data access, processing, and transmission}

Growing ability to access, process, and transmit data is at the core of the digital transformation of economies and societies (OECD 2019a) and is driven by three main developments:

- The increasing amounts of data accessible through the internet (including social networks) and as a result of the proliferation of devices and sensors (Internet of Things) - commonly referred to as big data. Total digital data created globally is expected to increase from 33 zettabytes in 2018 to 175 zettabytes by 2025 according to one estimate (Reinsel, Gantz, and Rydning 2018). ${ }^{5}$

- The increasing ability to interpret, manipulate, and transform (or process) data, including very large and diverse datasets, through data mining, predictive analytics, natural language processing and machine learning (and other types of artificial intelligence) and facilitated by the availability of software, platforms, and infrastructure services increasingly available through cloud computing.

- The increasing ability to communicate (transmit) the outcomes of data analytics as a result of the proliferation of internet and mobile phone users (particularly smartphones). Across Asia and the Pacific, Latin America, and North America, 73\% of people are expected to be internet users by 2023 (up from $56 \%$ in 2018) and $74 \%$ to be mobile users by 2023 (up from 69\% in 2018) (Cisco 2018a).

Digital transformation creates opportunities to improve the management of disaster and climate risks, as do the availability and affordability of financial protection tools:

- Increasing access to data can provide more comprehensive, accurate, and timely information on hazards, exposure, and vulnerability - and more timely and detailed information on impacts during and after a disaster-including in economies or regions that have traditionally faced limitations in data availability.

- Big data analytical techniques, increasingly available through software, platforms, and infrastructure that can be accessed in the cloud, can provide new capacity for processing the greater volume of data and identifying correlations and trends,

\footnotetext{
A zettabyte is a trillion gigabytes, equivalent to the storage capacity of approximately 250 billion DVDs.
} 
allowing an improved understanding of risks and impacts that can support more effective decision-making.

- The proliferation of internet and mobile phone (particularly smartphone) users, combined with increasing broadband and cellular data speeds, ${ }^{6}$ can support faster, broader, and more effective transmission of risk and risk management information.

\section{Emerging technologies and innovations for disaster risk management and financing}

\section{Data access technologies and innovations}

\section{Earth observation}

While not new, recent innovations in earth observation technologies have greatly increased the range of information and level of granularity available, as well as the reliability, affordability, and access to this technology. Technical advances and growing competition in space programs have driven down the costs of satellite imagery, with the price of highresolution imagery falling almost $50 \%$ in the last decade. ${ }^{7}$ The technology has also benefited from significant innovation that allows for

- increased coverage and resolution as more satellites in orbit provide very high resolution imagery globally while innovations in sensor hardware have increased the spatial (granularity) and temporal (frequency) resolution of imaging, including through the emergence of "high revisit" satellites;

- improved characterization of the built environment through the development and application of hyperspectral, Light Detection and Ranging (LiDAR) and Synthetic Aperture Radar capabilities (LiDAR sensors, for instance, are able to identify the type of construction material used in a given structure [e.g., concrete versus asphalt) from hyperspectral images and building heights], which are also able to provide imagery through cloud cover (which had been particularly problematic in tropical regions); and

- enhanced reliability as innovations in hardware and sensors have made earth observation infrastructure more reliable and durable, ensuring that in situ instruments are no longer vulnerable to natural hazards and can provide a robust source of near-real-time information.

Earth observation data is also increasingly available from aircraft, particularly unmanned aerial vehicles (or drones). Improvements in materials and electronic control systems have provided increasing drone range, along with the ability to attach high-resolution digital cameras, advanced global positioning technologies, and sophisticated computing power

6 According to one estimate, fixed broadband and cellular speeds are expected to double and triple (respectively) relative to 2018 on a global basis, with mobile speeds increasing almost fourfold in some APEC regions (Cisco 2018).

7 One commercial provider listed archival high-resolution imagery at $\$ 10-\$ 20$ per square kilometer and tailored new images for $\$ 20-\$ 30$ per square kilometer. 
(Estrada and Ndoma 2019). Declining drone costs (both acquisition and operation) are expected to lead to more than 2.6 million drones in commercial use worldwide by 2025 (compared to less than 400,000 in 2019) (Buchholz 2019).

\section{Street-level imagery}

Street-level imagery is increasingly available around the world, providing a three-dimensional view of the earth at ground level. There are a number of commercial and open-source providers of geocoded street-level maps populated by images collected by the companies directly or crowdsourced from users. Street-view maps are available for at least some parts of almost all APEC economies ${ }^{8}$ and fill important gaps in information on the built environment that is not available through aerial or satellite imagery. Improvements in the availability and affordability of camera technologies, such as omnidirectional imagery cameras which provide a $360^{\circ}$ image around the photographed location, will continue to enhance the coverage, quality, and frequency of street-level imagery.

\section{Connected devices}

The growing network of connected devices provides a new source of data on the physical parameters of the natural and built environment. Technological advances in the types and quality of sensors has increased their reliability and precision and has expanded the scope and interoperability within networks of connected devices. Sensors are also increasingly integrated into consumer goods. Smartphones, for example, often include pressure sensors (which can signal weather changes, storm development), proximity sensors and accelerometers (which can signal seismic activity). Technological advances have also allowed a greater diversity of devices to communicate with each other without human intervention. The implementation of $5 \mathrm{G}$ mobile networks will greatly expand the speed and capacity for information transmission from connected devices.

\section{Volunteered geographic information}

The increasing availability of information and images on the internet provides a real-time (and often geocoded) source of data that can be crowdsourced to complement other sources of data on natural and built environments. Images and information posted by individuals on social media (or social network) websites, for example, can provide updated information on impacts of weather events, such as an indication of the number of people or structures affected. The increasing availability of broadband internet connections and access to smartphones should facilitate continued growth in the usage of social networks (social network users are projected to increase from an estimated 2.95 billion in 2019 to 3.43 billion by 2023 [Statista 2020a]).

\section{Data processing and analytical technologies and innovations}

\section{Cloud computing}

Cloud computing is transforming the way society accesses software and hardware (DeStefano, Kneller, and Timmis 2019), providing individuals and businesses with access to on-demand information technology services via the internet, including software, platforms (such as application development platforms) and infrastructure (such as data storage and

8 For example, as of June 2020, Google Street View included street-level imagery from 20 of 21 APEC economies. 
servers). Among other benefits, the availability of cloud computing services provides greater access to low cost processing capacity (which is usually needed in the analysis of large datasets) and the latest technological developments, while also allowing users to access these services from anywhere with an internet connection. One recent estimate suggests that, by 2021, cloud computing data centers could process $94 \%$ of computing workloads (Cisco 2018b). Based on the share of information technology spending allocated to cloud computing (public cloud), only a few high-income APEC economies (including Australia and Canada) are (or are near) the level of cloud computing adoption reached in the United States. However, growth in spending on public cloud services is forecast to be near or above $20 \%$ per year in the People's Republic of China (PRC), Indonesia, Mexico, the Republic of Korea, and the Russian Federation, with the PRC expected to reach spending allocation levels similar to Australia and Canada by 2022 (Gartner 2019).

\section{(Big) data analytical tools}

A variety of tools have been developed to support the analysis of large volumes of data. These tools allow analysis of both structured and (increasingly) unstructured data (such as sensor data, images, e-mails, and social network data) to identify patterns, trends, and correlations. For example:

- natural language processing techniques can be applied to the analysis of large volumes of text-based data, such as e-mails, documents, and social media posts;

- pattern recognition techniques can be applied to the analysis of images to identify objects (or changes) in catalogues of digital images;

- speech-to-text conversion techniques can be applied to transform audio into searchable text (Davis 2019).

Artificial intelligence techniques apply algorithms to the analysis of large datasets and include machine learning techniques (algorithms that can learn from data without relying on rules-based programming) and deep learning techniques (a subset of machine learning composed of algorithms that permit software to perform tasks, like image recognition, by exposing multilayered neural networks to vast amounts of data) (Beal 2019). These technologies can provide four main types of analytics: (i) descriptive (analysis of current or past situations), (ii) diagnostic (analysis of causal factors for a given event), (iii) predictive (analysis of potential future scenarios), and (iv) prescriptive (analysis of actions that should be taken). Platforms such as GitHub provide open-source code and algorithms that enhance access to these types of analytical tools.

\section{Data transmission technologies and innovations}

The internet, social networks, and mobile phone apps have transformed the way information is communicated, and the increasing reach of broadband connections and internetconnected mobile phones will greatly expand the effectiveness and reach of communication through these channels.

Social networks are increasingly relied on as a source of information in a number of APEC economies. For example, a recent survey found that close to $70 \%$ of adults surveyed use 
social networks as a source of news in Chile; Hong Kong, China; Mexico; and the Philippines, and approximately 50\% in Australia and the United States (Statista 2020b).

Mobile phone apps provide new approaches to communicating information-allowing for greater interaction with users and advanced use of visualization tools. Downloads of mobile apps have increased by approximately 13\% annually since 2016 to reach 204 billion annual downloads in 2019 (Statista 2019). Smartphones, which provide the platform for the most sophisticated mobile apps, are expected to account for an increasing share of mobile phones in use globally (from 63\% of mobile phones in 2018 to $82 \%$ by 2023) leading to approximately 0.84 smartphones per capita by 2023 (Cisco 2018a).

Figure 2.1 illustrates how these emerging technologies and innovations can be applied to disaster risk management and financing. The next section describes the use of emerging technologies and innovation in risk and damage assessment. Sections 4 and 5 outline how emerging technologies and innovations can be used to apply improved risk and damage information to enhancing risk reduction and preparedness and to the financial management of disaster and climate risk.

Figure 2.1: Applications of Emerging Technologies and Innovation to Disaster Risk Management and Financing

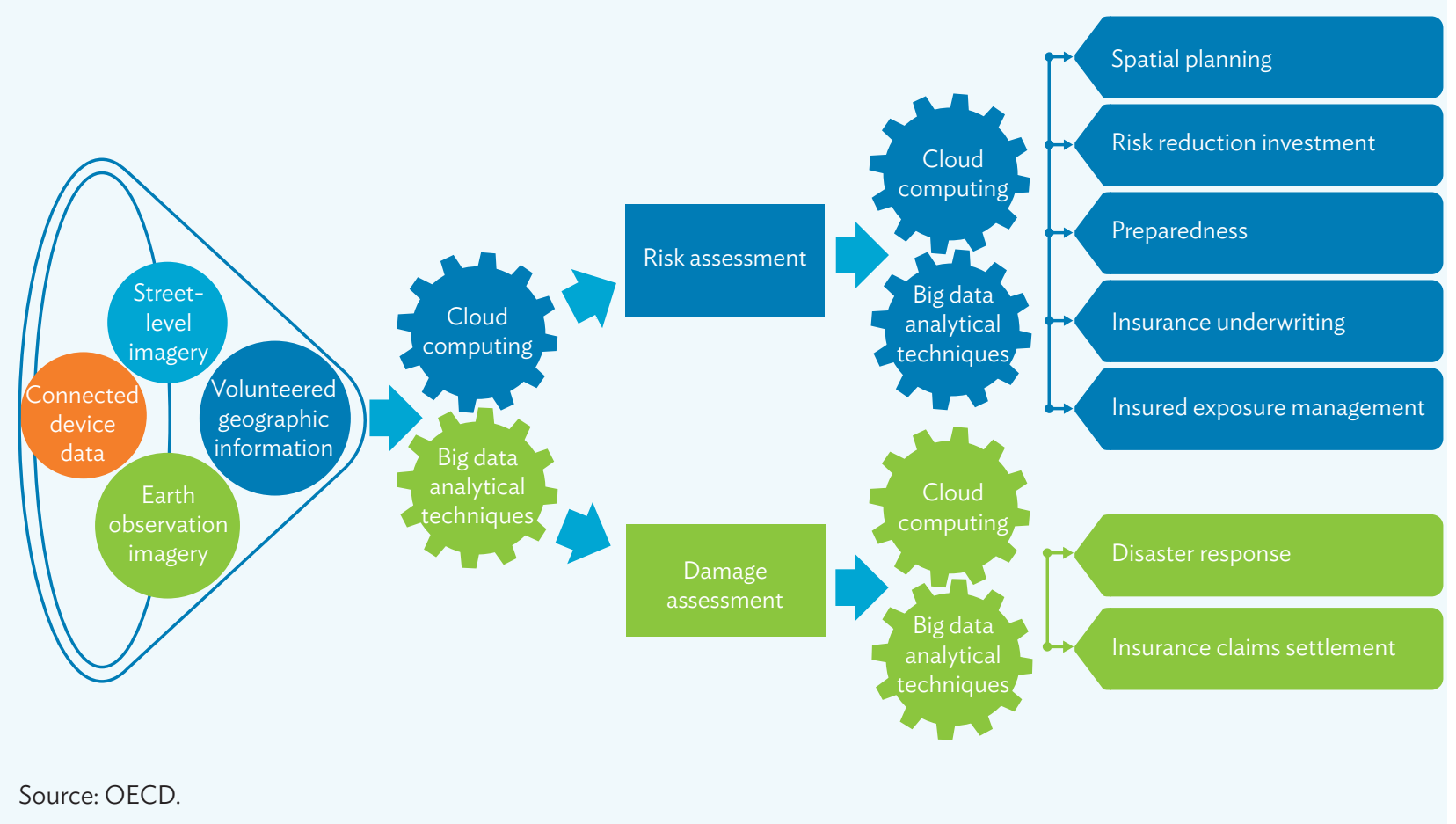




\section{The Contribution of Emerging Technologies and Innovation to Risk and Impact Assessment}

Emerging technologies and innovation can help reduce the impact of climate and disaster risks by improving risk and impact understanding.

Quantifying disaster risks (ex ante) requires an understanding of (i) the hazards that might impact a given location, including the physical parameters of those hazards such as wind speed, inundation level, or strength of ground-shaking (i.e., hazard); (ii) the people, buildings, and infrastructure present in a given location (i.e., exposure); and (iii) the resilience of communities, buildings, and infrastructure against the physical parameters of the hazard (i.e., vulnerability).

The quantification of disaster risk has depended extensively on historical experience of past disasters, building and infrastructure inventories, and engineering studies on structural vulnerabilities. The types of data sources used made it difficult to account for changes due to the evolving nature of hazards (e.g., in the context of a changing climate), exposures (e.g., in the context of changing land-use patterns and asset accumulation), and vulnerabilities (e.g., in the context of changes in building codes and enforcement and the level of protection offered by structural or nonstructural mitigation measures). These challenges have been particularly prevalent in emerging economies due to the more limited availability of historical data on the physical parameters of climatological, hydrological, or geological events (which also means that low frequency events may not be captured at all); incomplete inventories of the built environment; and less comprehensive data on the impacts of past catastrophes.

The quantification of disaster impacts (expost) requires an understanding of the geographical area impacted by the event, the size of the affected population, the severity of damage to buildings and infrastructure, and the production and income losses due to the disruption to economic activities (which may also be incurred in regions outside the area directly affected) (OECD 2018a). These data have traditionally been collected and aggregated by government agencies and other organizations by physically accessing the affected area, although the data collected through these methods have not always provided information on impact with sufficient granularity.

Advances in technology have facilitated significant improvements in the capacity to quantify disaster risks and impacts. Greater computational power, the propagation of weather stations and water level gauges, and the emergence of catastrophe modelling techniques have provided an increasingly trusted basis for the development of probabilistic risks assessments that give estimates of annual average losses and probable maximum losses based on a range of historical and hypothetical events. However, the reach of these techniques remains limited 
as many economies or perils are still uncovered ${ }^{9}$ and access to these tools is restricted by cost (as many of the most advanced models are developed by commercial firms). Challenges related to cost and access have led to a number of efforts to develop open-source solutions.

Technology has also improved the collection of data on ex-post damages and losses as government (or nongovernment) surveyors have been given access to connected mobile devices and tailored smartphone apps that facilitate data collection and more timely transmission of information to emergency management operations centers.

\section{Risk assessment}

\section{Hazard}

The expanding inventory of data and imagery related to past disaster and climate events and the growing ability to integrate and analyze this data can provide critical inputs for assessing potential hazards based on the physical parameters and footprints of past events.

As noted above, earth observation data and imagery is increasingly available for more parts of the world and at greater resolution, providing a growing library of high-quality images of the impact of hazard events. For example, the European Space Agency's Earth Observation for Sustainable Development program has established a Wetland and Water monitoring service that provides open access to monthly observations on land covered by water for all regions of the world. The imagery has been used to develop probability indices for the inundation of water on normally dry land which, over time, will provide an increasingly accurate illustration of flood risk at 20 meters spatial resolution (Kayitakire et al 2020). The program has also developed the Rainfall Explorer service, which can provide maximum 1-day, 5-day, and 30day precipitation levels for different return periods (10,20, 50, and 100 years) for areas across the world based on data from 1979 onward. The service can also be combined with data on past flood events from the Dartmouth Flood Observatory for better understanding of the impact of precipitation levels on flooding (Nobakht 2020). A satellite mission (Surface Water and Ocean Topography) planned to begin in 2021 will provide measurements of water elevation and inundated areas around the world and is expected to contribute significantly to the reach and accuracy of flood modelling (Frasson et al. 2019).

Individuals' use of social networks to describe their environment is an additional source of data on hazard footprints to complement less frequent imagery or, where installed, data from sensors such as flood or tidal gauges or seismometers. In some cases, crowdsourced volunteered geographic information from social networks has been found to be as-if not more-accurate than hydrological and geological sensors. For example, in Chile, data from earthquake-related social network posts have been found to provide a similar view of seismic activity as data from geological sensors (Green 2020). A study in the United States found that an analysis of social network posts provided a more comprehensive picture of coastal flooding impacts in many coastal areas than could be derived from the network of tidal gauges, particularly for lower tide heights (Moore and Obradovich 2020).

9 The development by commercial firms of catastrophe models for specific perils and regions tends to be linked to the amount of private insurance coverage acquired for that peril in that region, as the main clients of catastrophe modelling firms are the insurers providing coverage. As a result, regions or perils with limited private insurance coverage are often not prioritized for model development by commercial firms. 
Advances in data processing and analytical capacity have significantly increased the ability to generate (and assess the impacts of) large numbers of hazard scenarios, greatly improving the risk and probability measures that can be derived through catastrophe models. The application of (big) data analytical techniques to earth observation imagery, volunteered geographic information, and/or data from connected devices allows for a more comprehensive analysis of causal and correlated factors and can provide a better understanding of risk-overcoming some of the challenges to traditional approaches to risk assessment. For example, by training an algorithm with flood gauge data from past floods, researchers at Texas A\&M University in the United States have been able to develop a model for predicting the flow of water during extreme precipitation events that takes into account the performance of the drainage network. According to the researchers, the model was able to simulate the water flow from a major flood in 2016 with 85\% accuracy (Suresh 2020). Similarly, in Japan, data from a 2018 heavy rainfall event in Okayama Prefecture was used to train an algorithm to predict flood impacts in the future and was successfully applied to model flooding from Typhoon Hagibis in 2019 with a high-level of accuracy when compared to the post-event flood maps generated by local government (Moya, Mas, and Koshimura 2020). The application of these techniques also allows risk modelers to assess more complex multihazard scenarios (such as a flood caused by an earthquake-generated landslide [Green 2020]), identify, monitor, and measure potential sources of accumulation risk-and to take into account a changing climate. For example, one United States-based company is using artificial intelligence and machine learning techniques to provide risk scores for wind, flood, fire, and other climate for specific buildings or regions for up to 50 years (Jupiter n.d.). As outlined in section 4 below, these techniques are also being applied to underwriting insurance and other financial protection tools.

\section{Exposure}

The improvements in the resolution and coverage of earth observation imagery as well as the increasing ability to integrate different data sources on the natural and built environment can fill important gaps in the availability of data on exposure-particularly in regions without well-developed or updated building and infrastructure inventories.

Space-based earth observation imagery can now provide sufficient resolution to map exposure (i.e., the built and natural environments, including buildings and infrastructure as well as crops and natural ecosystems) and can also provide complementary estimates of population distribution based on characteristics such as nighttime light (Le Cozannet et al. 2020).

Street-level imagery, gathered by companies such as Google or Mapillary or crowdsourced through platforms such as OpenStreetMap (or both) can provide additional data on the characteristics of the built environment that may not be available through earth observation, such as occupancy, shared walls, and connecting roofs, as well as information on the structural condition. These technologies can also provide platforms for initiatives aimed specifically at addressing gaps in information on the built environment. For example, in Viet $\mathrm{Nam}$, the Missing Maps initiative supported an effort to enhance Vulnerability Capacity Assessments for flood risk undertaken by the Viet Nam Red Cross. It did this with geocoded street-level imagery incorporated into OpenStreetMap to provide a more accurate assessment of the spatial layout of local communities and their potential exposure to coastal floods and storm surge (Duong and Levine 2018). 
More recently, artificial intelligence techniques (particularly pattern recognition techniques) are being applied to derive better exposure information from earth observation imagery. For example, an algorithm was trained to identify bridges from earth observation imagery of Uganda and was able to find 70 bridges that had previously not been accounted for in streetlevel imagery maps or census data (Intel 2020).

\section{Vulnerability}

Improvements in the resolution of earth observation imagery also allow relevant information to be derived for assessing the vulnerability of exposed assets. Satellite imagery has sufficient resolution to provide basic structural characteristics (building shape, materials) that can be complemented by other survey methods including sample visits to provide assessments of structural vulnerability to different types of hazards (Le Cozannet et al. 2020). For example, one assessment of structural vulnerability to earthquakes in Padang (Indonesia) found that a model using satellite imagery verified by sample site visits was able to provide a catalogue of municipal building vulnerability with fairly high accuracy (error rate of 10\%) (Geiß, Klotz, and Taubenböck 2014). Earth observation data can be supplemented by street-level imagery as well as data gathered by lower-altitude imagery (aircraft or drones) to more accurately assess structural vulnerability. In some cases, insurance companies are relying on this type of data for underwriting insurance coverage (see section 4).

Big data analytical techniques are also providing improved methods for monitoring the vulnerability of structures over time. For example, researchers in the United Kingdom have used deep learning to train an algorithm to assess the integrity of bolt connections in steel frame structures (e.g., bridges, dams) using accelerometers (a sensor that measures acceleration), which has the potential to greatly enhance the accuracy and efficiency of structural health monitoring methods (Zhang, Biswal, and Wang 2019). In Guatemala, artificial intelligence analytical techniques applied to earth observation and street-level imagery have been used to identify structures susceptible to collapse in the event of an earthquake. The approach was able to identify approximately $85 \%$ of the buildings identified as vulnerable based on traditional civil engineering assessments (GFDRR 2018).

A comprehensive assessment of vulnerability to hazards should also account for other factors beyond the structural vulnerability of buildings or infrastructure. Earth observations of nighttime light intensity can provide useful information on local population levels (Le Cozannet et al. 2020). Big data analytical techniques such as machine learning and deep learning have been successfully used to analyze earth observation and street-level imagery to identify indicators of poverty and well-being in regions in Africa and India not wellcovered by census data (Lee et al. 2020; Yeh et al. 2020). A similar approach was applied to identifying businesses most vulnerable to damage and disruption from an earthquake in the San Francisco Bay Area (United States) (Gupta, Wein, and Haveman 2019).The Humanitarian OpenStreetMap initiative is working to integrate self-reported information on access to water and housing conditions with its geocoded street-level imagery data.

Figure 3.1 illustrates how these emerging technologies and innovations can be applied to disaster risk assessment. 
Figure 3.1: Applying Emerging Technologies to Risk Assessment

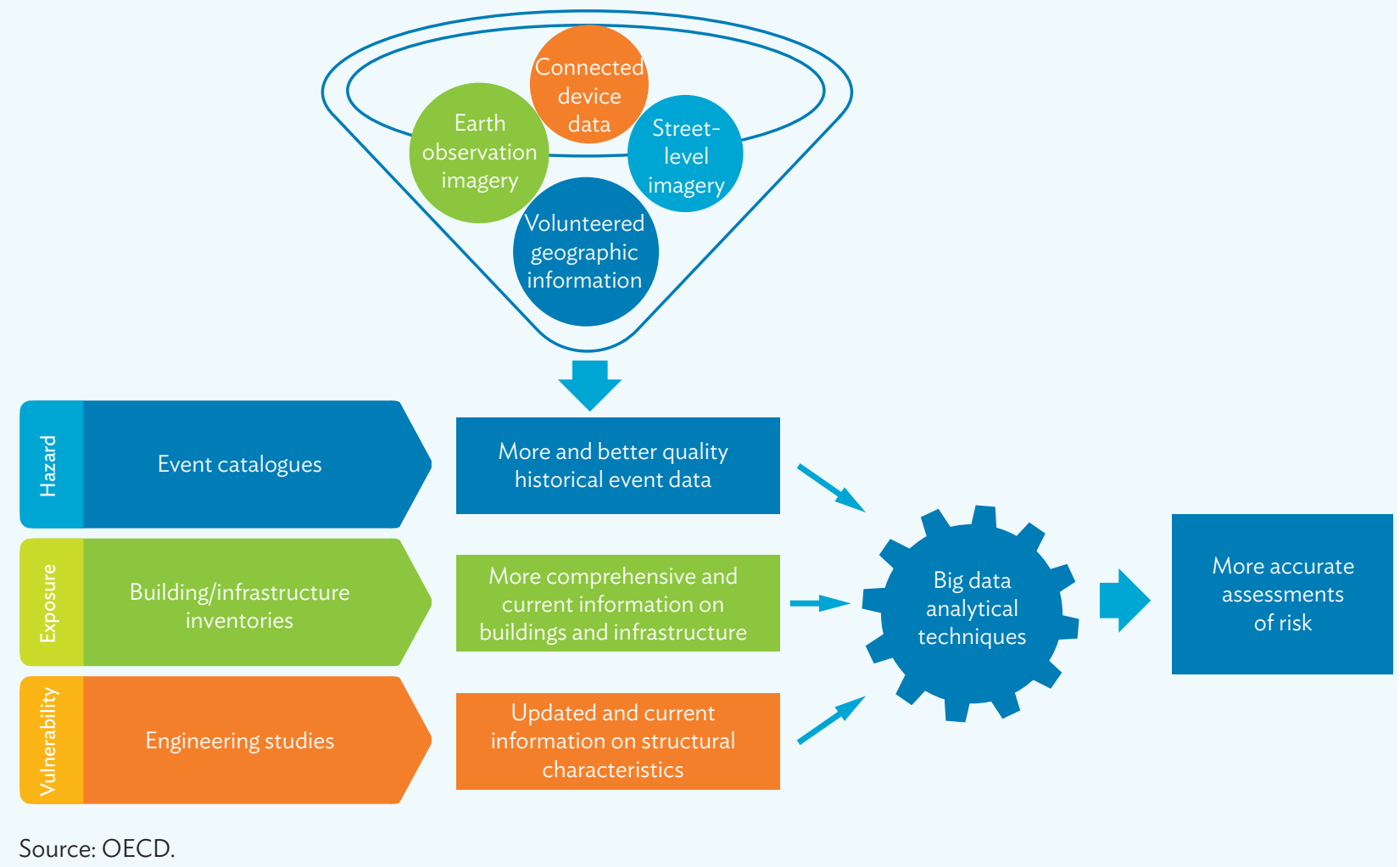

\section{Damage and impact assessment}

Emerging technologies are making a particularly significant contribution to increasing the speed and accuracy of disaster impact assessments. Cloud computing technologies, combined with the development of tailored mobile phone applications, have greatly enhanced the speed and efficiency of collecting damage information by individual assessors. For example, a mobile rapid damage assessment app, automatically synced to the cloud, has been developed for use by engineers in Haiti for assessing damage to individual buildings after disaster events (Miyamoto International and USAID 2019).

Earth observation imagery now available provides sufficient resolution to assess the area impacted by a disaster event (e.g., land not previously covered by water, buildings and infrastructure assets that have sustained structural damage, and declines in nighttime light intensity indicating disruption to energy availability or demand). The large and increasing number of satellites in circulation provide a pass-over frequency that makes it possible to generate imagery to facilitate impact assessment within hours or days of the occurrence of the event. For example, the Copernicus Emergency Management Service, a service established to provide earth observations from European satellites for emergency management, was able to provide authorities with before and after satellite images of Tacloban City (Philippines) within 4 days of the occurrence of Typhoon Haiyan. The image resolution provided sufficient granularity to identify sections of the city destroyed, highly affected, moderately affected, 
or possibly affected (Paunan 2020) (satellite images were also used for settling claims [Swiderek and Wipf 2015]). A feasibility study has recently been completed on expanding this service to provide an automated flood monitoring tool based on earth observation imagery that would be available globally (Matgen et al. 2020).

As in the case of risk assessment, satellite-generated earth observation imagery can be supplemented by other forms of aerial imagery (aircraft and drones) and street-level imagery. For example, in the Philippines, the Philippine Red Cross and American Red Cross collaborated on the Tindog Tabang Leyteño project that used drone and street-level cameras to develop maps of areas affected by Typhoon Haiyan to inform the recovery effort. In the aftermath of Hurricane Maria in 2017, a team of assessors used street-level imagery to provide accurate mapping of damage across the entire affected island of Puerto Rico (United States) (Higgins 2018).

Connected sensors can provide real-time information on a variety of physical characteristics, such as temperature, water pressure and level, and the presence of smoke, among others, which can provide critical information on geographical areas impacted by a flood or wildfire (Tremaine and Tuberson 2017). Geocoded data from smartphone accelerometers, which measure proper acceleration (i.e., an object's acceleration due to external factors rather than own motion) can be harnessed to measure the intensity of earthquake shaking in different locations to provide real-time information on where damage may have occurred.

Sensor data can be supplemented by leveraging volunteered geographic information on the damage and impacts from individual posts on social networks. Many governments (particularly emergency management agencies) around the world have developed specific smartphone apps to collect this type of information, including the Federal Emergency Management Agency (United States) (Adamski 2019), the state government of Andhra Pradesh (India) (Ghosh 2020), and Badan Nasional Penanggulangan Bencana (Indonesia) (Ogie et al. 2019). While these crowdsourcing applications face challenges (such as user takeup and accuracy of reporting (Ogie et al. 2019, Sukhwani and Shaw 2020), some studies have shown that crowdsourced data can provide relatively high accuracy in identifying impacted areas. For example, one global study involving the application of a geoparsing algorithm to Twitter posts related to flooding allowed for the correct detection of $90 \%$ of flood events reported in Munich Re's NatCatService database (and many that were not included in the database) (de Bruijn et al. 2019).

Big data analytical techniques can be applied to leverage these data sources for damage assessments. Change detection algorithms can be applied to earth observation imagery to quickly identify impacted geographic regions and damage to individual buildings and infrastructure. For example, one platform based on change detection using artificial intelligence was able to provide a complete mapping of the 2019 floods in Ottawa (Canada) and an inventory of flooded infrastructure and buildings in less than an hour-a process that often can take 5 days (Opt/Net 2020). Another study applied a change detection algorithm to pre- and post-earthquake imagery of buildings in Port-au-Prince (Haiti) and Bam (Iran) and was able to correctly classify damaged buildings in 93\% of cases (Khodaverdizahraee, Rastiveis, and Jouybari 2020). A group of researchers at the University of Texas at Austin trained a machine learning algorithm with data from Hurricane Harvey to more quickly 
analyze requests for assistance posted on Twitter and identify those in need of rescue (Devaraj, Murthy, and Dontula 2020).

Data analysis platforms have been developed to facilitate the integration of data and imagery from various sources to provide comprehensive postdisaster damage assessments. The I-REACT project, funded by the European Commission, has developed a platform to integrate emergency management data from various traditional and innovative sources, including earth observation imagery, historical event data, and weather forecasts, as well as volunteered geographic information, drone imagery, and data from connected wearables (I-REACT n.d.).

Figure 3.2 illustrates how these emerging technologies and innovations can be applied to damage assessment.

Figure 3.2: Applying Emerging Technologies to Damage Assessment
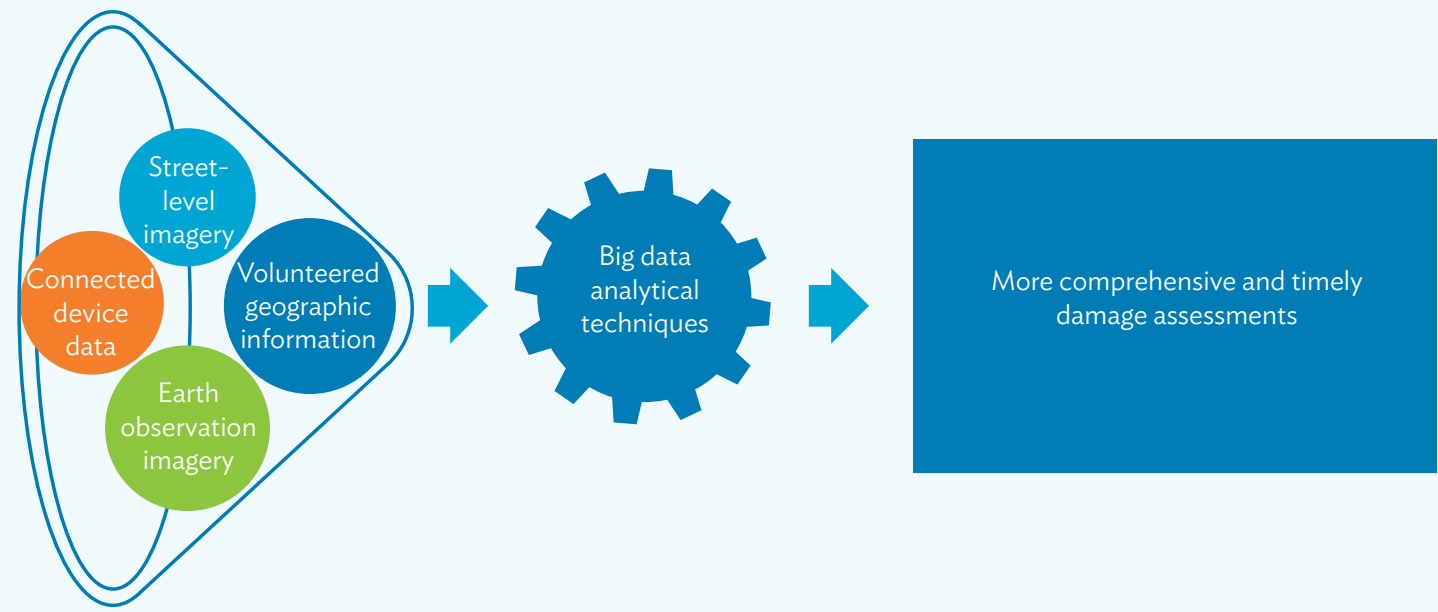

Source: OECD 


\section{Applications of Emerging Technologies to Risk Reduction and Preparedness}

Improvements in risk and damage assessment can be applied to enhance the effectiveness and efficiency of land use and spatial planning, risk reduction investments, preparedness, and disaster response. Emerging technologies and innovations, such as big data analytical techniques, can also be applied to support better decision-making in all of these areas.

\section{More effective land use and spatial planning}

Land-use and spatial-planning policies play a critical in role in risk management and in determining the level of future exposure to disaster and climate risks, particularly in urban areas. Rapid unmanaged urbanization is a significant factor in increasing the vulnerability of urban populations, especially the urban poor.

In most economies, local and regional governments have significant responsibility for landuse and spatial-planning decisions, although national governments often provide guidelines or frameworks for implementation at local levels. Local governments face three main challenges to implementing risk-sensitive land-use planning:

- access to sufficiently detailed data on hazard, exposure, and/or vulnerability;

- access to the modelling and decision-making tools to derive a resilience-oriented land-use plan; and

- capacity to monitor and enforce land-use and spatial-planning requirements (for example, ensuring no illegal construction in areas identified as high-risk, such as seismic or flood-prone areas).

The emerging technologies and innovations described above can be leveraged to address these challenges. Improved access to data and imagery through earth observation, streetlevel imagery, connected devices, and crowdsourcing volunteered geographic information can fill important gaps in the understanding of hazard, exposure, and vulnerability. Big data analytical techniques are increasing the capacity of existing tools for spatial analysis. The sophistication and capacity of spatial (or geospatial) analysis tools (i.e., software platforms that integrate data and imagery on the attributes of the natural and built environment into models based on geographic coordinates) has increased significantly through the integration of big data sources and the use of algorithms as tools for analysis (i.e., geocomputational methods) (de Smith, Goodchild, and Longley 2020). Access to these tools has also increased as open-source software platforms and spatial analysis tools become increasingly available 
in the cloud. Innovations in cloud computing technology that enhance throughput between users and the cloud-based software-combined with increasing broadband connection speeds-should address connectivity challenges and improve the utility of cloud-based spatial analysis over time (Altaweel 2020).

Earth observation imagery can also support improved monitoring and enforcement of landuse and spatial planning policies. More frequent and higher-quality imagery from satellites should provide the necessary resolution to monitor land use across all regions and could potentially be combined with change detection analytical techniques to automate the identification of breaches of land-use policies.

\section{Better targeted investment in risk reduction}

Structural (e.g., flood barriers) and nonstructural (e.g., building codes) risk reduction investments can make an important contribution to managing risks to people, buildings, and infrastructure in areas prone to disaster and climate hazards, including those developed before the associated level of risk was known. Numerous studies have demonstrated the benefits of investments in risk reduction. One comprehensive global examination of structural and nonstructural risk reduction investments for all types of natural hazards found that, using a consistent cost-benefit analysis approach, the vast majority of investments (102 of 117) resulted in benefits that exceeded costs (Hugenbusch and Neumann 2016). An assessment of costs and benefits of adopting model international building codes ${ }^{10}$ in the United States found that the benefits would exceed costs 12 times for earthquake risk, 10 for wind risk, and 6 for river flooding - with overall benefits of 11 times the cost of adopting the codes (NIBS 2019).

However, despite these benefits, most economies underinvest in risk reduction. For example, between 1991 and 2010 , only $12.8 \%$ of the estimated $\$ 106.6$ billion in development assistance allocated to disaster risk management was invested in risk reduction (Tanner et al. 2015). This underinvestment is generally driven by both technical challenges (such as difficulties in assessing the costs and benefits of risk reduction investments) and political impediments (e.g., such as governance failures, limited public resources and high opportunity costs, shortterm horizons of elected officials, difficulty in demonstrating benefits of avoided losses) (Vorhies 2012, OECD 2014).

The emerging technologies and innovations described above can address some of the technical challenges that impede investment in risk reduction. Improvements in risk assessment capacity, including greater accuracy in the identification of hazard-prone regions and structures at risk, should allow better decisions on the investment of scarce risk reduction resources. Emerging technologies and innovations can also enhance the processing and analytical capacity of decision support systems. Such systems are technology (software) tools that support decision-making by facilitating the comparison of different options for (in the context of natural hazards) risk management (e.g., through a calculation or visualization of the costs and benefits of different approaches). These tools are particularly valuable for

10 See footnote 1 on page 1. 
decision-making in complex problems involving multiple actors and/or significant uncertainty (Newman et al. 2017). In particular, improvements in data integration and optimization capabilities (e.g., through the application of artificial intelligence) have greatly improved the capacity of decision support systems while the availability of open-source software has increased access to these tools.

More effective communication of risk (and potential risk mitigation approaches) -enabled by innovations in internet- and smartphone-based risk visualization tools-can also address some of the informational challenges that impede investments by households and businesses in risk reduction. Increased access to broadband and cellular networks and smartphone penetration provides the infrastructure to achieve broader reach for these types of tools and the valuable information they can provide.

\section{Improved preparedness}

Increasing communities' preparedness and implementing effective early warning systems can greatly reduce disaster and climate risks. In the context of imminent emergencies, the ability to provide timely and accurate information on risk and likely impacts can save lives and significantly reduce damage and loss. Emerging technologies and innovations can enhance the timeliness and accuracy of hazard forecasts and support broader and more effective communication of coping strategies.

\section{Improvements in hazard forecasting}

Advances in the understanding and modelling of climate phenomena have greatly increased the accuracy of forecasting over time. For example, in the United States, the track error for tropical cyclones (i.e., average error in forecasting the path of the eye of a tropical cyclone) has declined since 1990 from approximately 100 miles to 50 miles for 24-hour forecasts and from 300 miles to 100 miles for 72 -hour forecasts (Schleifstein 2019). The application of big data analytical techniques to the increasing amount of available data on disaster and climate risks is significantly improving forecasting capacities - and therefore allowing more time to react to an impending hazard. Various combinations of earth observation imagery, data from connected devices, and big data analytical techniques are being applied to the monitoring and forecasting of different hazards:

- Flood: Earth observation imagery, data from connected devices, and volunteered geographic information crowdsourced from social networks are increasingly being used to provide real-time forecasting of flood risks in different regions of the world. Satellite-generated precipitation data is available from a number of sources and increasingly accurate as a result of the integration of ground-level data and the application of big data analytics. Some of these sources can provide data with little or no time delay. For example, Japan Aerospace Exploration Agency's Global Rainfall Watch data is available in real-time and, since 2019, for all regions of the world (Perera et al. 2020, OECD 2017d). Developments in modelling techniques allow precipitation data to be applied to real-time flood risk forecasting. For example, a United Kingdom-based company has developed a software tool (FloodMap Live) that uses rainfall forecasts along with high-quality topographic and hydrological data to provide real-time surface water flood risk maps (Previsico n.d.). Increasingly 
sophisticated cameras with high-speed connections to control centers are being used to monitor water levels and water flow and discharge characteristics. For example, in the Métropole Toulon Provence Méditerranée region of France, cameras equipped with infrared projectors for nighttime monitoring and connected to image analysis and processing software are being used to monitor water levels and flow velocities in real-time for all of the region's major river basins (Tenevia n.d.). Crowdsourced volunteered geographic information from social networks is also being harnessed for real-time forecasting. In Jakarta (Indonesia), for example, social network posts on Twitter have been leveraged to provide real-time mapping of floods and have demonstrated a relatively high-level of accuracy when compared against post-event imagery (Perera et al. 2020). In Japan, a system to detect heavy precipitation events has been developed by applying natural language processing techniques to the identification of tweets related to heavy precipitation in a given location and to validating the social network data against sensor data to provide users with maps showing heavy precipitation hazards (Iwakura et al. 2018). In Kolkata, the Asian Development Bank has supported the development of a cloud-based earlywarning system that integrates data on rainfall and water levels generated by sensors installed by public authorities in strategic locations as well as by small businesses that have been encouraged to install low-cost sensors outside their premises (ADB 2018a). In the PRC, disaster risk management officials are implementing a range of emerging technologies to monitor and visualize flood risk during the annual rainy season (Box 4.1).

- Wildfire: Earth observation, connected devices, and artificial intelligence techniques are also being used to improve the forecasting of wildfire risk. Earth observation imagery can provide regular information on vegetation growth to ascertain the fuel loads that drive wildfire potential. In Australia, a satellite with infrared technologies that is specifically calibrated to monitor the dominant local vegetation (eucalyptus and shrub) is under development to provide improved wildfire forecasting accuracy (Amos 2020). A California Forest Observatory has been established to dynamically map wildfire risk at the level of individual trees across the state using increasingly available high-resolution imagery and data on weather, climate, population settlements, and infrastructure that will be analyzed using artificial intelligence techniques (O'Shea 2019). One company has developed a camera and sensor system, using optical and thermal cameras and a spectrometric system for identifying chemical properties, that can identify fires in remote areas (up to 15 kilometers away) using artificial intelligence techniques that analyze the generated imagery against the properties of past fires (Sullivan 2019, Compta Emerging Business n.d.).

- Landslide: Earth observation imagery providing precipitation data and information on indicators of landslide susceptibility has been integrated into a model developed by the United States National Aeronautics and Space Administration to provide real-time forecasting of landslide risk globally. The Landslide Hazard Assessment for Situational Awareness model monitors rainfall levels that could trigger landslides and matches that data against landslide susceptibility factors such as recent forest fire or tree removal, proximity to tectonic fault, bedrock strength, and land grade to provide a real-time assessment of potential landslide risk that is updated every 
30 minutes (NASA Global Precipitation Measurement Mission 2018). According to one estimate, the model would have provided false positive landslide warnings in $3 \%$ of cases and true positive warnings for $60 \%$ of the landslides that have occurred historically (GFDRR 2018). In the PRC, a potential disaster was recently avoided as imagery from the BeiDou Navigation Satellite System facilitated the detection of a geological anomaly in the aftermath of heavy rainfall, allowing local officials to organize an evacuation in advance of the landslide (which occurred on 6 July) (Meiping 2020).

- Earthquake: While it is possible to calculate the probability that a major earthquake will occur in a given area over a given period of time, it is not possible to specifically predict exactly when a major earthquake will occur (USGS n.d.) - which is one of the reasons major earthquakes have often resulted in significant damage and loss of life. However, the application of big data analytical techniques can provide more rapid verification of the occurrence of an earthquake (and its characteristics) which can provide critical early warning that can support preparedness, particularly in communities farther from the epicenter. Earlier warning can provide additional time for evacuation, preventative shutdowns of power and transport services, and other mitigation measures to save lives and reduce disruption. In the PRC, for example, researchers have applied artificial intelligence techniques to the measurement of earthquake properties that will allow measurement of important parameters such as epicenter, magnitude, and depth within two seconds of the earthquake (with greater accuracy than traditional methods) (Dai 2020). One group of researchers has developed a smartphone application that can be used to harness data from smartphone accelerometers to enhance early warning and measure shaking intensity (Kong et al. 2016). More recently, Google announced that it will begin collecting geocoded data from the accelerometers included in its devices to provide early detection of earthquakes in regions around the world (Dave 2020).

- Temperature extremes: Big data analytical techniques are also being applied to improve weather forecasting. For example, a group of researchers has applied deep learning techniques to identify patterns of atmospheric circulation present before past heat waves and cold spells to create a model that can highly accurately forecast such climate extremes 1 and 5 days in advance (Sima 2020).

Improved imagery, data, and analytical techniques have also been used to model longer-term weather characteristics, including variations in the El Niño/Southern Oscillation-a periodic warming of sea surface temperatures in the Pacific and Indian oceans that has historically led to a variety of climate risks, including flooding and droughts. While models exist to predict when an El Niño may occur and with lead times of approximately 1 year, a recent application of deep learning to identifying patterns in sea surface temperatures was able to provide accurate forecasts 18 months in advance and with greater detail on the zonal distribution of sea surface temperatures (Ham, Kim, and Luo 2019). Greater advance warning would allow households and businesses to implement more substantial risk mitigation strategies. For example, farmers could integrate advance information on future weather patterns into decisions on the types and varieties of crops they plant. 


\section{Box 4.1: Assessing Rainy Season Flood Risk in the People's Republic of China}

The annual rainy season in the People's Republic of China is often marked by significant flooding in regions adjacent to the Yellow River, its second-longest river and home to well over 100 million people. To manage flood risk, disaster risk management agencies have been leveraging emerging technologies to provide a continuous view of water levels and flood risk. Improved forecasting techniques are allowing earlier (and more accurate) warnings of heavy rainfall events and convective storms. Earth observation imagery from satellites and drones is being generated for more than 300 large and medium-sized reservoirs throughout the basin, while connected flood gauges are used to monitor and transmit information on water levels in smaller tributaries in mountainous regions. Artificial intelligence is applied for realtime assessment of flood risk. In Anqing City, a local telecoms operator has connected $360^{\circ}$ cameras through a $5 \mathrm{G}$ cellular network to virtual reality goggles to provide flood monitoring personnel with real-time images of water levels.

Sources: Meiping (2020), Shuang (2020)

\section{Communicating warnings and information on effective coping strategies}

Effective early warning systems can save lives and reduce property loss from natural hazards, and a number of studies have demonstrated the relationship between improvements in early warning and reductions in mortality and damage ${ }^{11}$ (Rogers and Tsirkunov 2010). The effectiveness of an early warning system depends on (i) the reliability of the system in its ability to monitor, detect, analyze, and forecast hazards while minimizing false alarms; (ii) awareness of - and trust in - the early warnings among the targeted population; (iii) ability to disseminate and communicate this information to the population at risk: ${ }^{12}$ and (iv) ability of the targeted population to understand and appropriately respond to the information provided. Improvements in the accuracy and timeliness of hazard forecasting can support more effective communication of early warnings by (i) increasing forecast accuracy, which should build confidence among those vulnerable to an impending hazard and encourage them to take mitigating steps; and (ii) providing earlier warning, which should allow more time for the vulnerable to implement appropriate coping actions.

The increasing reach of broadband connections and internet-connected mobile phones will greatly expand the reach of early warning communications through the internet, social networks, and mobile phone apps. Large technology companies are already harnessing this capacity to provide early warning information to relevant users of their products. For example, during the Australian bushfires in 2019-2020, both Google and Facebook worked with government agencies and emergency responders to provide emergency management information to users potentially affected or at risk from the fires (Haritos 2020).

1 For example, if provided with sufficient warning of a flood, those at risk would have an opportunity to move high-value items to higher ground and therefore ultimately reduce the overall level of damage.

12 The ability to quickly communicate warnings faces technical and governance challenges. For example, an assessment of the effectiveness of the tsunami early-warning system in the 2018 Palu-Donggala Tsunami found that system limitations in the ability to forecast a tsunami triggered by a submarine landslide as well as the need to secure local approval of evacuation orders (among other factors) reduced the time available for individuals to effectively evacuate (UNDRR and UNESCO-IOC 2019). 
Technological developments and innovations have also allowed increasing automation of early warning communication. For example, in Colombia, a network of water level and air temperature sensors has been installed along major river systems that, with the support of an installed mesh network to address weaknesses in the cellular network, provide automated warnings to relevant local officials when a potential hazard is detected. Big data analytical techniques offer opportunities to automate the integration of forecast information on hazards into early warnings and communications on appropriate coping strategies. For example, the Odisha State Disaster Mitigation Authority in India has developed a web and smartphone-based platform (SATARK) that translates generic weather forecast information into early warnings of impending hazards and provides tailored advice on coping strategies in response to the identified hazard. The platform also applies a machine learning algorithm that allows the platform to learn from captured events over time (Srikanth 2019). In Japan, a smartphone application has been developed to provide users with real-time information on the potential for water inundation at their current location as a result of an earthquakegenerated tsunami as well as information on possible evacuation routes (Fujitsu Global 2019). A group of researchers in the United States has developed a model that makes use of heuristic algorithms to optimize evacuation plans based on minimizing travel time to an available emergency shelter (Dulebenets et al. 2019), which might eventually lead to the ability to develop evacuation plans that take into account the impact of hazard forecasts.

\section{More efficient disaster response and/or recovery}

Efficient disaster response and recovery is critical for saving lives and minimizing damage and disruption in the aftermath of a disaster event. A comprehensive assessment of damages and impacts provides the basis for developing relief and recovery strategies by identifying populations in immediate need of assistance and prioritizing communities and assets in recovery measures.

In the short term, an initial damage assessment provides the information necessary for targeting rescue operations and disbursing assistance (whether in the form of financial aid or supplies). The provision of rescue and relief and the delivery of aid are often complex operations which present logistical and technical challenges. Effective rescue and relief efforts require coordination between a multiplicity of actors, often both domestic and international, including government agencies, the military, humanitarian organizations, the private sector as well as volunteers. The delivery of support must often overcome a host of logistical challenges, which are exacerbated by the effect of disaster impacts on rescue operations, for example, where access routes and communication channels have been destroyed, buildings are at risk of collapse, earthquakes aftershocks are expected, or toxic pollutants have been released.

As outlined above, technological developments and innovations in earth observation imagery from satellites as well as drones, street-level imagery, connected devices, and volunteered geographic information from social networks-together with the ability to integrate these different data sources and apply big data analytical techniques to the processing of this information-can greatly increase the rapidity and accuracy of damage assessments. More timely and accurate information on affected populations and damaged structures and infrastructure assets should on its own allow more efficient relief and recovery operations. 
However, big data analytical techniques can also be applied to optimize various elements of the relief operation. The I-REACT data integration platform described above includes a decision-support tool that can help guide emergency management planning (I-REACT n.d.). A group of researchers have applied algorithms to developing a model for estimating relief supply demand based on volunteered geographic information from social networks and other data on the affected region that can help emergency managers optimize the distribution of relief supplies (Schempp et al. 2019). These techniques can also be used to identify potential critical infrastructure services at risk and pre-position the necessary technicians, equipment and materials to facilitate quick recovery. In preparation for Hurricane Florence in 2018, for example, a major energy services provider in the United States states of North Carolina and South Carolina used artificial intelligence techniques to determine where to pre-position the technicians necessary to achieve a quick restoration of power in case of damage to transmission lines (Seto 2018).

Some recent technologies can also help address some of the logistical challenges that accompany disaster relief and response efforts. In particular, drones can be used to both deliver emergency supplies and provide emergency telecommunications. For example, drones were used to deliver emergency medical supplies in the United States state of North Carolina in the context of the COVID-19 health emergency (Porter 2020). They have also been used to provide cellular network coverage in disaster zones. In the aftermath of Hurricane Maria in 2017, a large helicopter-like drone attached to a ground power source was deployed to Puerto Rico (United States) to provide continuous 4G cellular network coverage (Russon 2018). Mobile payment systems offer a means to disburse financial assistance quickly and safely to those in need. These systems can also be used to transfer resources within communities to those in need. One study in Rwanda, for example, found evidence that mobile airtime transfers (as an alternative to mobile funds transfers which were not available at the time) within social networks increased significantly in the aftermath of the 2008 earthquake in the Lake Kivu region, suggesting the effectiveness of this technology for providing support to affected friends and family (Blumenstock, Eagle, and Fafchamps 2016).

Emerging technologies can also help address some of the communication and coordination challenges related to disaster response and recovery. For example, in the Republic of Korea, the Ministry of Interior and Safety has developed a Disaster and Safety Information System that integrates geocoded information from across government ministries to support both risk assessment and response (OECD 2020c). 


\section{Applications of Emerging Technologies to the Financial Management of Disaster and Climate Risks}

As outlined earlier, the financial costs of responding to disaster events are substantial and likely to increase as a result of a changing climate and continued asset accumulation. Governments absorb a significant share of these costs, particularly in economies with lessdeveloped insurance markets.

In 2017, the OECD Council approved a Recommendation on Disaster Risk Financing Strategies that aims to provide high-level guidance for governments on the development of strategies to manage these costs. To support efforts by economies to effectively manage these risks, $\mathrm{ADB}$ has developed a tool kit to identify the elements of a supportive enabling environment (Box 5.1).

\section{Box 5.1: Building Financial Resilience to Disaster Risks: Guidance for Policymakers}

In 2017, the OECD Council adopted a Recommendation on Disaster Risk Financing Strategies (OECD 2017a) that provides guidance on the development of strategies for the financial management of disaster risks. It provides a set of high-level recommendations for designing a strategy for addressing the financial impacts of disasters on individuals, businesses and subnational levels of governments, as well as the implications for public finances:

- Supporting the availability of data and technology necessary for the quantification of disaster risk and the identification of potential financial vulnerabilities-as the basis for making effective decisions on risk management and underwriting insurance coverage for disaster perils;

- Establishing the elements of a regulatory framework necessary to support the ability and willingness of individuals, businesses and subnational governments to protect themselves against the financial impacts of disasters, including measures to support risk awareness, risk reduction and the availability of affordable insurance and other financial protection tools; and

- Evaluating the potential risks to public finances posed by disasters and developing an approach to managing those financial demands.

In 2020, the Asian Development Bank released a country diagnostic tool kit which outlines the key elements of an enabling environment for disaster risk financing and provides guidance for countries on how to self-assess their policy and regulatory framework against this set of key criteria (ADB 2020). At the time of writing, the assessment tool has been applied in Fiji, Nepal, Pakistan, and Sri Lanka (ADB 2019b, 2019c, 2019d, 2019e). 
Similar to the other components of disaster risk management, addressing the financial impacts of disaster and climate risks begins with a sound understanding of potential risk to enable the development of a functioning insurance market and inform strategies for managing the impacts on public finances.

\section{Enhancing the availability and affordability of indemnity insurance}

A significant share of economic losses from disasters are uninsured, particularly in middleincome economies. Most damages and losses from earthquakes, wildfires, floods, and storms are uninsured because the share of homes, businesses, and government assets with applicable insurance coverage is low or the share of losses covered by insurance is limited by low policy limits or large deductibles. Low insurance penetration is usually the result of a gap between the willingness-to-pay (or capacity-to-pay) for insurance coverage and the cost of insurance-although in some cases, insurance for a given peril is simply not available. ${ }^{13}$ Improvements in the availability and affordability of insurance coveragecombined with increased awareness of the value of insurance in providing financial protection-can make an important contribution to increasing penetration and reducing the gap between economic and insured losses (often referred to as the protection gap).

Insurance (and reinsurance) markets contribute to building financial resilience by (i) providing those affected with access to a (relatively) quick source of funds for reconstruction (allowing for a quicker recovery); (ii) reducing the financial stress on households and business that would otherwise need to absorb those losses; and (iii) limiting the impact on public finances (as governments will often need to provide financial assistance to affected households and businesses without sufficient insurance coverage). A number of analyses have examined whether there is an empirical relationship between levels of insurance coverage and the severity of economic impact. These analyses found (in general) that:

- The uninsured portion of catastrophe-related losses drive macroeconomic costs, whereas well insured catastrophes have insignificant or even positive effects on economic activity (Von Peter, Von Dahlen, and Saxena 2012).

- Countries with high insurance penetration have smaller contractions in output from a disaster and their debt levels remain virtually unchanged (Melecky and Raddatz 2011). An additional $1 \%$ in insurance penetration was found to reduce the disaster recovery burden on taxpayers by $22 \%$ (Lloyd's 2012).

- Severe disaster events (i.e., modelled 1-in-250 year events) can have important economic impacts and implications for public finances and sovereign ratings. Higher levels of insurance coverage of the assets damaged or destroyed by a natural

13 There are a number of factors that impact the demand for-and supply of-insurance coverage. Insurance demand (and therefore, willingness-to-pay) may be lower where there are low levels of financial literacy or risk awareness, lack of trust in insurance companies/products or the existence of alternative sources of funding for post-disaster recovery and reconstruction. The supply of insurance may be low if the level of risk is high, there is a lack of data to assess risk or operational and distributional costs are high. For more information on demand and supply challenges, see OECD 2018c, OECD 2016, and Surminski and Vivid Economics 2018. 
catastrophe can, to some extent, mitigate the medium-term economic impact and the sovereign ratings impact of catastrophe events (Standard \& Poor's 2015).

- Greater use of property catastrophe reinsurance coverage has been found to have a positive impact on reducing the economic disruption of past catastrophe events (OECD 2018b).

Insurance markets can also contribute to reducing the level of overall risk by developing analytical tools to support improved risk assessment and more effective risk management decisions and by providing incentives for risk reduction through premium pricing.

A number of factors impact the availability and affordability of insurance coverage. Homes, businesses, and public assets in areas prone to natural hazards will normally face higher insurance costs than those in lower risk areas. Similarly, buildings and infrastructure that are more vulnerable to damage from wind, water, fire, or ground-shaking based on their construction will also face higher premiums. As a result, more effective land use and spatial planning and better targeted investments in risk reduction can lower the aggregate cost of insurance coverage. In addition, the availability and affordability of insurance coverage can be enhanced by lowering the cost of underwriting insurance coverage, managing exposures, distributing insurance products, and settling insurance claims as these costs are ultimately borne by policyholders through the premiums they pay.

\section{Lowering the cost of underwriting}

To underwrite insurance coverage for a household, business or public entity, insurance companies need to understand the hazards that could impact the assets of the policyholder and the vulnerability of those assets to the physical characteristics (wind speed, water level and flow velocity, earthquake magnitude, etc.) of those hazards. Traditionally, underwriting insurance coverage has been undertaken through manual processes involving the completion of questionnaires on location and structural characteristics and, in the case of larger value policies, a site visit by an assessor. Underwriters use hazard and/or risk maps (where available) to establish the potential exposure to natural hazards and engineering studies or knowledge to assess potential structural vulnerability. Where available, catastrophe models have simplified (and improved) the underwriting process by providing a platform for risk assessment of individual properties although these models are not available for all perils in all regions and can involve significant costs to implement. As a result, underwriting costs can account for a significant portion of insurance premiums - particularly in regions where data on hazard and vulnerability are difficult or expensive to acquire. Even in developed insurance markets where quality risk data is more widely available, underwriting expenses in the nonlife insurance sector can account for $20 \%-25 \%$ of the gross premiums written.

The increasing access to data and imagery from earth observation satellites and aircraft, street-level cameras, connected devices and crowdsourcing of volunteered geographic information-and the enhanced ability to integrate and analyze this data and imagery through big data analytical techniques-is also being leveraged by insurance companies (and insurance service providers) to lower the cost of underwriting insurance coverage. For example, some service providers have developed platforms that provide instantaneous risk reports and scores covering storm, flood, earthquake, and wildfire for any address in 
the United States based on an assessment of available geospatial data (HazardHub n.d., Betterview n.d.). Another company uses artificial intelligence techniques to combine aerial imagery of structural characteristics and other relevant factors such as elevation and vegetation proximity with historical and simulated data on potential hazards to provide additional insights on potential risk to support underwriting decisions (Zesty.ai n.d.). In some cases, the additional risk insight has increased the availability of coverage (see Box 5.2) and/or reduced the cost of coverage. For example, one company offering flood insurance coverage underwritten based on earth observation imagery and artificial intelligence analytical techniques can reportedly offer coverage at a $25 \%$ lower cost than what is available through the United States National Flood Insurance Program (Neptune Flood n.d.).

Earth observation imagery can play a critical role in monitoring cultivation and yields for the extension of agricultural insurance (Mcintosh and Mansini 2018), (Rotairo et al. 2019), (ADB 2018b), either on a stand-alone basis or in combination with field survey data to address gaps in coverage (Guan et al. 2018). One recent study found that the use of publicly available Google Earth imagery for measuring the size of cultivated land in the Lao People's Democratic Republic, the Philippines, Thailand, and Viet Nam provided sufficient accuracy to serve as a cost-effective alternative for validating self-reported information from farmers (Dillon and Rao 2018).

Many insurance companies are using improved access to data and big data analytical techniques to automatically underwrite their insurance coverage. In the United States, for example, at least three entrants to the home property (and/or contents) insurance market use external data collection and big data analytical techniques to automatically underwrite coverage-including for catastrophe perils-based on the address of the property and a few additional questions on occupancy, basic construction characteristics, and belongings (Hippo n.d.; Lemonade n.d.; Neptune Flood n.d.). Established insurance companies are also

\section{Box 5.2: Enhancing Availability of Insurance Coverage for Wildfire Risk}

In some cases, new data and analytical techniques can contribute directly to the availability of insurance coverage for some risks. In the United States state of California, increasing losses from wildfires amid a changing climate and continued development in the wildland-urban interface has led to significant declines in the availability of home insurance coverage in some parts of the state. According to the California Department of Insurance (CDI), insurerinitiated nonrenewals of homeowner insurance policies have increased significantly in recent years in communities close to areas affected by recent wildfires (CDI 2019a)-which has led CDI to impose a 1-year moratorium on home insurance nonrenewals by insurance companies (CDI 2019b).

In response, a number of insurance companies are developing better ways to assess wildfire risk by integrating new data and analytical techniques. One company has developed a new model for wildfire risk that applies artificial intelligence-based predictive analytical techniques to earth observation imagery to get a more accurate assessment of wildfire risk at the level of individual homes (Delos Insurance n.d.). The company has partnered with a specialty insurer to provide coverage to lower-risk policyholders that were deemed high-risk by other insurance companies (Insurance Journal 2020). Another company has applied artificial intelligence techniques to define a set of secondary factors (fire resistant building materials, landscaping) that could reduce the risk of fire even among houses located in high-risk fire zones with the aim of improving the insurability of homes that have these characteristics located in high-risk zones (Sams 2020).

Source: Authors. 
leveraging these technologies to gather relevant external data and automatically underwrite coverage for specific market segments (Holmes 2018). In the PRC, ZhongAn has developed a cloud-based system for underwriting property policies that can reportedly generate a response to applicants in less than a second (Sheng et al. 2017). One service provider has developed an underwriting platform for wildfire and wind risk for use by insurance companies that automates building inspection by analyzing spatial imagery on proximity to vegetation, roof geometry, and other factors using artificial intelligence and deep learning (Cape Analytics n.d.). Another has developed an automatic underwriting platform tailored to small value insurance coverage in developing markets (Inclusivity Solutions n.d.). One company in Ireland has developed an automatic underwriting platform for launching insurance coverage based on parametric triggers (see below) (Blink Parametric n.d.).

\section{Managing exposure}

Insurance companies manage their exposure to the risks that they underwrite by holding capital and/or transferring risk to reinsurance markets. If there is significant uncertainty about the level of covered risk (due, for example, to minimal data on hazards or vulnerability), the amount of capital that the insurer will need to hold and the cost of reinsurance will normally be higher (particularly to account for low frequency, high severity events). ${ }^{14}$

As noted above, emerging technologies and innovations can potentially improve the accuracy of risk assessments by integrating greater amounts of data on hazard and vulnerability and applying advanced analytical techniques to measure the level of risk, including the potential for risk accumulation as a result of interconnectivity and pervasiveness of risk exposures. These techniques can be applied to help quantify probable accumulation of risks in various scenarios (such as disasters and in cases of serial aggregation) and improve the accuracy (and reduce the uncertainty) in underwriting insurance coverage. A number of insurance services providers have developed platforms that use big data analytical techniques to help insurance companies integrate external data sources into the underwriting process and improve overall pricing accuracy. These platforms can integrate external data (e.g., from earth observation and other data sources) on construction characteristics, elevation, building perimeter, occupancy as well as financial and business information to both supplement and verify the information submitted through traditional insurance coverage applications (Convr n.d.; Cytora n.d.). At least one service provider has developed a platform that provides relevant risk information for all regions and disaster and climate perils (Insurdata n.d.).

Emerging technologies and innovation also offer opportunities to make the process for ceding risk to reinsurance companies more efficient. Distributed ledger technology is being used to develop smart contracts between insurers and reinsurers to increase automation in the placement of reinsurance coverage and the execution of that coverage in response to a triggering event. B3i, a company established by insurance and reinsurance companies, is testing this approach for property catastrophe excess of loss placements. If successful, this approach could significantly reduce transaction costs and lead to a reduction in the cost of reinsurance coverage for natural catastrophe losses.

14 For high-risk properties, more accurate and granular assessments of risk would lead to higher premium prices and could ultimately reduce the availability and affordability of insurance coverage. In such cases, the most cost-effective approach is likely to make investments in risk reduction in order to support the affordability of insurance coverage. 


\section{Insurance distribution}

The cost of distributing (selling) insurance policies to households and businesses also accounts for a significant part of the premium cost. Insurance products may be distributed directly by insurance companies or through intermediaries such as agents or brokers (or banks, where bancassurance models are permitted). Intermediaries are paid commissions by the insurers or fees by the policyholders for their role in advising on and securing insurance coverage (OECD 2020a). Commission expenses account for approximately $10 \%-15 \%$ of gross written premiums in most economies in the case of property insurance (OECD 2020)..$^{15}$

Emerging technologies and innovation are having a significant impact on how insurance products are distributed. An increasing share of standardized insurance coverage that does not involve the provision of advice (e.g., motor vehicle insurance) is being distributed through price aggregators and online price comparison platforms (OECD 2020a). For example, in the United Kingdom, the share of motor insurance coverage distributed through price aggregators had already reached 53\% of gross written premium in 2017 (Kaesler, Lorenz, and Schollmeier 2018) (and is likely closer to 70\% currently) while home insurance distributed in this way accounted for $26.7 \%$ of distribution in 2019 (GlobalData 2020).

Many insurance companies are also using emerging technologies and innovations to develop new approaches to distributing their insurance coverage. For example, one company has developed a platform that can be used by companies in other sectors to offer various forms of insurance coverage (including property insurance coverage) to their customers. The platform provides automated underwriting based on big data analytical techniques with the insurance company providing coverage for the risk underwritten as well as required policy administration services (Insurance Journal 2020, iptiQ n.d.). In Africa, some agricultural insurance programs are attaching insurance to the purchase of seeds and are making it simple for farmers to acquire insurance by scanning a barcode included in seed packaging and allowing farmers to insure very small amounts (ACRE Africa n.d.).

New distribution channels for insurance coverage for catastrophe perils could contribute to lowering transaction costs (and therefore premiums) and lead to an increase in insurance penetration. However, there is also a risk that the gains in speed and efficiency offered by these new distribution mechanisms might come at the cost of a reduction in the amount of advice given to policyholders on the coverage being offered (which is normally provided by experienced intermediaries). Ideally, emerging technologies and innovation should also contribute to providing advice to policyholders on the coverage that they need-for example, by using innovations such as risk visualization tools and robo-advisory to provide policyholders with tailored information on the risks that they face.

\section{Claims settlement}

Claims submitted by policyholders (for indemnity-based insurance coverage) must be investigated by insurance companies to determine the amount of damage, the likely cost of repairing the damage, and the amount covered under the terms and conditions of the insurance policy. This has traditionally involved the dispatch of a claims adjuster to

15 OECD Insurance Statistics, database, https://stats.oecd.org/Index.aspx?.DatasetCode=INSIND (accessed July 2020). 
inspect the extent of damage to an insured property. This process can involve significant costs-particularly in the context of a disaster event that affects multiple policyholders simultaneously and where there may be impediments to accessing the property due to transport infrastructure disruption or unsafe conditions. The cost of adjusting claims can be a significant component of the price of insurance coverage. In the United States, for example, the cost of adjusting home insurance claims accounted for $7.1 \%$ of premiums written in 2018 (III n.d.).

The increased access to data and imagery and ability to integrate and analyze this data that has led to improvements in the speed and accuracy of impact assessments can also contribute to improving the claims adjustment process and reducing related expenses. These developments are particularly relevant for large-scale catastrophes where significant claims adjustment capacity will be required to inspect damage to multiple buildings.

In the first instance, improvements in forecasting can help insurance companies position claims adjustment resources in advance of a catastrophe to accelerate the adjustment process and pay claims more quickly. One company is using satellite imagery and machine learning to help insurance companies predict potential damages to property up to 4 days in advance of a hurricane (Insurance Journal 2019). Innovations in camera technology and image analytics are also providing claims adjustors with tools to assess damages with greater speed and accuracy. For example, one company has developed a camera for use in claims adjustment that scans the interior of a damaged building to provide time-stamped images and full interior dimensions through the application of artificial intelligence techniques (Poran 2020).

As noted, earth observation imagery provided by satellites offers sufficient resolution to identify areas that have been impacted by a disaster and have incurred damages. The imagery from satellites can be supplemented by aerial imagery provided by drones to provide sufficient information to complete damage assessments for individual buildings. A number of service providers are offering comprehensive damage information or even fully automated loss adjustment reports to insurance companies using satellite, drone, and other imagery (including pictures or videos submitted by policyholders) analyzed with artificial intelligence techniques, including change detection algorithms (Kirk 2019, Zesty.ai n.d., Lemonade n.d., Tractable n.d.). According to one estimate, the use of these tools could reduce loss adjustment expenses by as much as 75\% (Park 2019).

Distributed ledger technologies may offer further opportunities to automate the claims adjustment process through the use of self-executing smart contracts (Pandey 2020). Smart contracts use internal and external data to automatically validate whether a claim meets the terms and conditions of coverage and execute a payment if so. Digital payment systemsand particularly mobile payment apps-provide a means to quickly and safely disburse funds to policyholders that incurred covered losses and therefore can support a quicker recovery.

\section{Risk reduction}

Improvements in the effectiveness of communications tools, combined with increased access to broadband internet connections and smartphones, provide new opportunities for insurance companies to support risk mitigation by their policyholders. For example, insurance 
companies around the world have created smartphone apps that allow their policyholders to access information on risk reduction measures that they can take as well as to receive early warning information in case of an imminent risk.

Emerging technologies and innovation in connected devices have the potential to enhance the contribution of insurance to risk reduction. While still in its infancy, a number of insurance companies have begun to encourage the use of connected devices such as water leak detectors and smart smoke detectors among their policyholders by offering discounts on premiums for policyholders willing to install these devices and share the generated data with insurance companies. One company offers a package of connected devices (water leak and freeze detector, smart battery for smoke detectors and a garage door sensor) for insurers to provide to their policyholders to detect potential water inundation, fire and theft (Roost Home Telematics n.d.). An increasing number of insurance companies are offering their policyholders smart home connected device packages as a risk mitigation service (Meagher 2019).

In addition, improvements in the ability to set premiums based on accurate assessments of risk should support more effective risk-based pricing of insurance coverage (where permitted). Risk-based pricing can provide important incentives to policyholders to invest in risk reduction to benefit from lower premiums. Figure 5.1 illustrates how these emerging technologies and innovations can be applied to improve the affordability of insurance coverage.

Figure 5.1: Improving the Affordability of Insurance Coverage

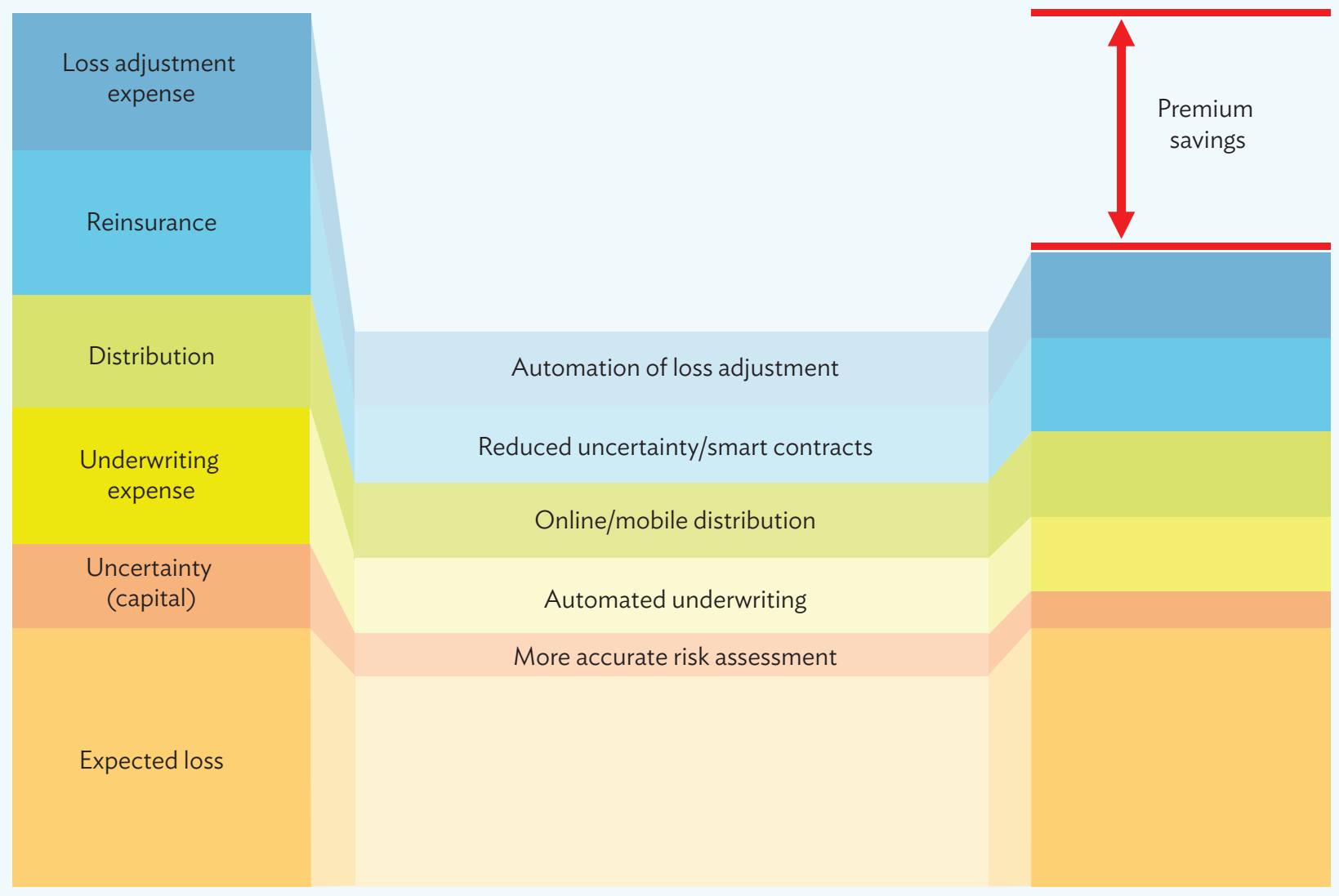

Source: OECD. 


\section{Parametric insurance solutions}

Emerging technology and innovation could also provide an opportunity to make greater use of parametric insurance coverage. Parametric insurance coverage is a type of coverage triggered by the occurrence of a disaster event that meets specific thresholds-often a physical parameter such as water level, wind speed, precipitation amount, or earthquake magnitude-and makes claims payouts of a fixed amount regardless of the amount of damage incurred by the policyholder (unlike indemnity insurance which pays claims based on the amount of damage or loss incurred by each individual policyholder). There are numerous different approaches to establishing a trigger, including using a modelled loss threshold (i.e., a threshold loss figure derived using a catastrophe model) or applying a trigger that requires that both a physical parameter threshold is met and a loss has been incurred by the policyholder.

Parametric insurance has been used to provide financial protection against a number of different types of risks in economies around the world. It is often applied to the coverage of agriculture risks using precipitation data generated from connected weather stations to identify whether there has been sufficient (or excessive) rainfall for growing a given insured crop (ACRE Africa n.d.). Parametric insurance has also been used to provide coverage for livestock in Kenya using a trigger based on whether grazing conditions would put livestock at risk using the color of the ground (an indicator of dryness) in imagery gathered through satellite observation (Swiss Re n.d.). Parametric insurance is also used to provide funds for relief and recovery expenses in the Caribbean and Central America by CCRIF, an insurance company that provides coverage to public sector members for excess rainfall, earthquake, and tropical cyclone events (CCRIF SPC n.d.). Various forms of parametric triggers are also applied in risk transfer to capital markets (catastrophe bonds, industry-loss warranties, etc.). According to one estimate, parametric written premium may be as high as $\$ 5$ billion globally and set to grow at a rate of 9\% annually (Carrigan and Spies 2020).

A few parametric insurance products to protect households and businesses against catastrophe perils have been developed:

- In the United States state of California, one insurance company is providing set payments of $\$ 10,000$ to household policyholders in zones affected by severe shaking as defined in maps released by the United States Geological Survey after an earthquake event and where the policyholder has confirmed that they will incur resulting expenses (Jumpstart 2018). Parametric insurance coverage for hurricane damage that provides payouts based solely on the strength and proximity of the hurricane to the policyholder are available in the United States states of Florida and Hawaii (StormPeace n.d., First Insurance Company of Hawaii n.d.). Swiss Re has designed a parametric product for businesses to cover hail damage in the United States that scales payouts based on the size of the hail stones (Insurance Journal 2020). The school board in the United States state of Louisiana has acquired a parametric insurance coverage that pays out up to $\$ 1.25$ million if a named storm produces winds of 80 miles per hour for at least 1 minute (Alexander, Grenier, and Brooks 2020). 
- A reinsurer and primary insurer have collaborated on the development of a parametric insurance product distributed and settled through a mobile app that will provide protection against typhoons in typhoon-prone regions of southeast PRC (Reinsurance News 2017).

- In the United Kingdom, one company is offering parametric insurance coverage for businesses against flood risk that is triggered at an agreed water level threshold as reported by a connected sensor that is installed at the insured property (FloodFlash n.d.).

The main advantage of parametric insurance is its simplicity as the coverage can be underwritten based solely on the probability of an event that meets the thresholds for payout occurring at a given location and claims payments are made solely on the basis of the occurrence of the triggering event. As a result, underwriting and claims adjustment expenses should be much lower than in the case of indemnity insurance and payouts should be made much more quickly allowing households and businesses to recover much faster. Parametric insurance also reduces the potential for moral hazard in indemnity insurance coverage as policyholders that invest in risk mitigation and therefore suffer lower levels of damage will still receive the same payout under a parametric insurance policy. The main disadvantage of parametric insurance is basis risk; i.e., the risk that the coverage is triggered when no loss is incurred or that the policy is not triggered when a loss has occurred (for example, if the specific threshold has not been met).

The increasing availability of data on hazards, exposure, and vulnerability and the improved ability to analyze this data using big data analytical techniques can provide a basis for developing parametric insurance coverage for more types of risks and with greater accuracy and therefore less potential for basis risk. Earth observation data and connected devices provide more data on the physical parameters of disasters that can be used as triggers in the design of parametric insurance coverage. Big data analytical techniques can be applied to achieve greater accuracy in risk assessment to increase the probability that payouts are made when damages or losses are actually incurred. Emerging technologies such as distributed ledger technology can be applied to automate the process of validating triggers and executing payments (Istuk, Ardic, and Allen 2020).

\section{Managing public finance response to disaster risks}

Major disasters can have important implications for public finances as governments will need to manage the costs of relief and recovery and reconstruction of publicly owned buildings and infrastructure. Where the level of insurance protection for damages and losses incurred by households and businesses is low, governments are also likely to be called upon to provide financial support to those affected.

These costs can be significant. A study by the OECD and World Bank presented to APEC finance ministers in 2018 estimated that annual post disaster expenditure by governments averaged approximately $\$ 340$ million in Mexico, $\$ 506$ million in Australia, and $\$ 23.6$ billion 
in Japan (OECD/World Bank 2020). ${ }^{16}$ The challenge for governments is to develop efficient strategies for funding these recurring costs to ensure that funds can be accessed to respond to disaster events when needed and without jeopardizing other important government spending priorities or financial or fiscal stability.

Governments use a number of strategies for funding disaster costs, including dedicated reserve funds, contingent financing, borrowing and risk transfer to insurance markets (OECD/ World Bank 2020). These different funding approaches have different implications in terms of opportunity cost, timely access to funds, and cost of funding. Uncertainty about the level of risk can lead to suboptimal funding strategies and ultimately increase the overall cost of disasters in both financial and social terms. For example, a government that underestimates the level of disaster and climate risk (and the impact on public finances) might not have the resources available to respond quickly to a disaster event which could lead to higher costs of recovery and reconstruction and longer disruptions to livelihoods.

The contribution of emerging technologies and innovation to more accurately assessing risk can equally support improved management of the public financial impacts of disaster and climate risks by providing governments with the information they need to better assess potential fiscal exposures (as well as for assessing the most cost-effective approach to reducing disaster risk). An improved understanding of risk can also support the use of risk transfer mechanisms by providing governments with the information that insurance, reinsurance, and capital markets require to assume public finance risk. Programs established to transfer public sector risk to insurance markets in Mexico (FONDEN reinsurance coverage and catastrophe bond), the Alianza del Pacífico economies (Chile, Colombia, Mexico, and Peru catastrophe bonds), the Philippines (catastrophe bond), the Caribbean and Central America (CCRIF insurance coverage) and Pacific island countries (PCRAFI insurance coverage) have all developed extensive assessments of risk to underpin the acquisition of (re) insurance coverage and/or the issuance of catastrophe bonds. The Southeast Asia Disaster Risk Insurance Facility, which aims to provide financial protection to the governments of Cambodia, the Lao People's Democratic Republic, and Myanmar and through a risk transfer program, is directly integrating earth observation imagery and big data analytical techniques into modelling and underwriting flood risk coverage (CIMA Foundation n.d.).

The contribution of emerging technologies and innovation to providing more rapid and comprehensive damage assessments can also be leveraged to help governments better allocate funds to areas of need. Increased forecasting capacity could allow governments to provide funding in advance of a disaster event to support preparedness by local governments and/or households in communities in danger. A number of humanitarian organizations are using forecast-based financing to reduce the impact of disasters on vulnerable households. One study examined the impact of a forecast-based cash transfer made to vulnerable households in Bangladesh in advance of 2017 flooding and found that those that received the cash transfer had improved access to food, accumulated less (high-interest) debt, and suffered from lower levels of stress during and after the flood period than those that did not receive the advance funding (Gros et al. 2019).

16 The study provides estimates of annual spending by governments on disaster risk management (ex-ante and ex-post) as well as the share that is spent pre- and post-disaster. The estimates above were derived by calculating the ex-post share of reported annual expenditures. 


\section{Leveraging Emerging Technologies and Innovation}

\section{Challenges and Recommendations}

The emerging data collection, data processing, and data transmission technologies and innovations described in the preceding sections can be applied across APEC economies:

- Earth observation imagery from satellites and commercial and open-source streetlevel imagery maps are widely available and increasingly accessible while the cost of drone technology has declined significantly in recent years.

- The cost of installing connected cameras and sensors to measure water levels, temperature, is declining.

- High and increasing levels of internet, social network, and smartphone usage across most APEC economies create large volumes of volunteered geographic information, additional street-level imagery, and smartphone sensor data that can potentially be harnessed to complement other sources of data.

- The widespread use of the internet and smartphone applications across APEC economies allows effective use of these technologies for transmitting information and providing financial support and claims payments through mobile apps.

- The processing capacity and analytical tools available through cloud computing platforms are generally available.

However, as discussed below, there are challenges to the effective implementation of some emerging technologies and innovations:

- Resilient communications infrastructure: Many emerging technologies rely on fast and reliable access to the internet which may be constrained if broadband and/ or cellular networks are less developed.

- Technical skills: Big data analytical techniques require high levels of expertise that may not always be sufficiently available in all APEC economies (high-income economies also usually face a shortage of individuals with these skills, relative to the level of demand). In addition, many of these techniques require significant amounts of quality data as inputs for analysis which may not be available across all APEC economies.

- Access to data and analytical technologies: The cost to achieve broad image and data coverage through earth observation and connected cameras or sensors can 
still be significant in economies with large landmasses and/or dispersed populations. In many APEC economies, there are some regulatory impediments to the use of drones which may impede their use for risk and damage assessments (including for underwriting insurance and settling claims). Privacy protection regulationincluding, where applicable, data localization requirements-could impede the use of data processing and analytical platforms depending on the types of data needed to be processed.

- Insurance regulatory constraints: The use of emerging technologies and innovation in insurance underwriting, exposure management, distribution, and claims settlement may be somewhat constrained by insurance regulatory requirements in many APEC economies - which might also impede the development of parametric insurance solutions.

- User awareness, acceptance and trust: The benefits of applying emerging technologies and innovations will only be leveraged if there is broad awareness of the benefits of technology applications and acceptance and trust in the outcomes generated through the use of these technologies.

The existence of significant synergies across emerging technologies and innovations calls for a strategic approach to integrating these tools into disaster risk management and financing. For example, the benefits of building significant capacity in developing big data analytics skills will only be realized if the infrastructure to collect the necessary data for use in these techniques is also established.

\section{Building an enabling environment for the application of emerging technologies and innovations}

\section{Investing in resilient communications infrastructure}

Reliable broadband and cellular communications networks that provide universal access, including in remote areas, are critical to the application of most of the emerging technologies and innovations described in this report. Widespread internet connectivity and higher smartphone penetration will increase the utility of applying these technologies:

- The coverage of crowdsourced street-level imagery and volunteered geographic information will be lower in areas with unreliable access to internet and cellular networks or limited smartphone penetration, potentially creating a bias in coverage that favors more developed regions-which could impact the accuracy of big data analytical techniques. It would also limit the value of these data sources for emergency response in regions with limited connectivity.

- The value of cloud computing processing and analytical functions could not be leveraged in areas without a reliable internet connection. 
- Forecasting capacities based on connected devices and smartphone sensors will be limited in regions with unreliable internet connections, impeding the ability to provide early warning and support preparedness. Early warning communication and insurance distribution would have to be based on other (less efficient) communication methods.

As noted above, access and usage of the internet and smartphones is increasing across APEC, although some regions still have limited connectivity and low smartphone penetration. There are also important gaps in women's access to information and communication technology relative to men - which has been identified as a potential reason for higher disaster mortality levels among women (Wadland 2020). For example, in Asia and the Pacific, approximately $54 \%$ of the male population used the internet relative to only $41 \%$ of the female population.

Increased investment in communications infrastructure, with a particular focus on underserved regions, would greatly enhance the ability to leverage the benefits of emerging technologies and innovation for the management of disaster and climate risks.

\section{Developing technical skills}

Many of the emerging technologies and innovations described in this report, particularly those related to data processing and analytics, require a high level of technical skills that may not be sufficiently available in all APEC economies (including both the technology-related skills to develop and implement emerging technologies as well as the financial analysis skills needed to apply the outputs to financial management decisions). A lack of necessary technical skills could, in particular, limit:

- Processing and analysis of large volumes of imagery and crowdsourced volunteered geographic information.

- Integration of hazard, exposure, vulnerability and damage data from different sources.

- Development of algorithms for the analysis of risk and damage, forecasting and to support decisions on risk reduction, emergency response, insurance underwriting, and claims settlement.

These technical skills can be developed over time through integration of relevant content into school and university curriculums. In the short-term, APEC economies can encourage the development of these skills locally through various forms of knowledge transfer, such as:

- Training programs offered by data providers, such as those offered by the European Space Agency and the United States National Aeronautics and Space Administration on the use of earth observation for managing disaster and climate risks. The European Space Agency provides training to government officials and scientists on the use of earth observation imagery for disaster risk management (among other applications) (ESA n.d.). For example, in February 2020, the Asian 
Development Bank sponsored a capacity building workshop in Indonesia on how to use the European Space Agency's cloud-based Geohazards Exploitation Platform to monitor the progress of post-earthquake reconstruction in Sulawesi (ESA 2020). The National Aeronautics and Space Administration offers an Applied Remote Sensing Training program to educate disaster risk managers, among others, on potential applications of earth observation imagery (NASA 2019).

- Partnerships and exchanges between disaster risk management agencies and research centers (domestic or international) to access technical expertise and foster longer-term collaboration. For example, the Integrated Research on Disaster Risk's Knowledge Action Network on Emergent Risks and Extreme Events could provide a source of information exchange and expertise for officials with responsibility for disaster risk management.

- Partnerships, exchanges and/or technology agreements between disaster risk management agencies and the (re)insurance sector (including local branches or subsidiaries of international [re]insurance companies) to explore the potential application of technologies and innovations used in insurance underwriting and claims settlement to disaster risk and impact assessment.

Market access for foreign insurance and reinsurance companies could also support the transfer of emerging technologies and innovations. Globally active insurance companies that establish branches or subsidiaries (including joint-ventures) in foreign markets can introduce new technologies and innovations to the local market. Similarly, the reinsurance companies that have access to technologies and innovations implemented around the world will often collaborate with local insurers on product innovations where that collaboration will lead to risk sharing arrangements between the local insurer and reinsurer. Regulations that restrict foreign ownership of insurance companies or the transfer of risk to cross-border reinsurers could inhibit the transfer of technology and innovation (OECD 2020).

\section{Improving access to data and analytical technologies}

The integration of emerging technology and innovation depends on the ability of government agencies and (re)insurance companies to access sufficient input data and the processing and analytical tools necessary to implement big data analytical techniques.

Data processing and analytical technologies may require significant amounts of data to leverage the benefits of improved analysis. For example, artificial intelligence techniques require large amounts of data to train the algorithms to identify the correlations that are relevant to assessing hazard, exposure, vulnerability and impacts. Ensuring access to data is therefore critical for leveraging the benefits of these technologies.

In many economies, the volume of historical data that can be used to train algorithms on the impacts of past events may be limited. Damage assessments from past disaster events may not be comprehensive (or may not have been completed at all). Data from connected devices or volunteered geographic information from social networks may only be available with broad coverage for more recent years. The use of drones to capture aerial imagery may 
be limited by air traffic regulations. In some economies, commercial operators of drones are allowed, although with restrictions (such as line of sight or daytime only operation) and may require authorization for each operation which would limit their utility in disaster impact assessment (Park 2019, Property Drone Consortium 2018, Measure and American Red Cross 2015). In other economies, commercial drone use is not permitted (Insurance Development Forum 2019).

Data access might also be restricted by government regulation or commercial copyright. In particular, privacy protection regulations may restrict the sharing of data to specific purposes - which may not include purposes related to assessing disaster and climate risks. There may also be barriers to sharing some forms of data with foreign entities as a result of data localization requirements which could restrict the ability of disaster risk management agencies and/or (re)insurance companies to leverage technologies and innovations available from foreign providers.

Access to data processing and analytical technologies developed by commercial entities may be impeded by licensing costs. While licensing fees and patent protections are critical to incentivizing innovation by private sector entities, there are examples in other sectors of mechanisms that balance the need for innovation incentives with the public good value of the innovation. For example, The Vaccine Alliance incentivizes the development of vaccines as well as innovations in vaccine supply chains and delivery by making long-term purchasing commitments that encourage manufactures to produce vaccines and invest in innovation (Gavi n.d.).

Governments can invest in data collection infrastructure to improve the availability of data -while ensuring that the basic building blocks of national data collection systems such as national statistical offices and geospatial agencies are supported (OECD 2017b). Initiatives that encourage collaboration between national statistical offices and geospatial agencies could more efficiently address data needs.

Governments can also provide access to core data in their possession, such as earth observation imagery or data from government-owned connected devices and promote open access to relevant data collected by other parties in a way that maintains privacy protection (e.g., through the use of data anonymization techniques). Specific regulations could also be developed to allow the safe use of drones.

International organizations and bilateral development assistance providers can support access to data processing and analytical technologies for the purpose of improving disaster risk management. This could include the funding of technology transfers and licensing fees as well as the development of open-source frameworks. For example, a number of development assistance providers have supported the development of catastrophe models in lower income economies, both commercially developed models as well as open-source models such as the Oasis Loss Management Framework. One of the major initiatives of the Insurance Development Forum is to make insurance sector modelling capacity more widely available. 


\section{Adapting insurance regulatory frameworks}

The regulatory framework for insurance companies has an important impact on the ability of insurers to integrate emerging technologies and innovations into underwriting, exposure management, distribution, claims settlement and new product development. Insurance supervisors are primarily concerned with ensuring that insurance companies are financially sound and able to meet their obligations to policyholders (prudential supervision) and that policyholders are adequately protected against unfair practices by insurance companies or intermediaries (market conduct supervision). In some cases, the implementation of these objectives may unnecessarily constrain the adoption of innovative approaches by supervised insurers:

- Insurance supervisors will often oversee the premium pricing practices of insurers. In some economies, this involves (in the case of property insurance coverage) specific requirements for establishing premiums, often based on a categorization of buildings based on construction type, occupancy and/or hazard zone. In other economies, insurers might be free to establish premium prices although subject to approval or review by the supervisor. While these practices aim to achieve important prudential (solvency) and market conduct (unfair pricing) objectives, they may in some cases limit the ability of insurance companies to implement some of the innovative approaches to underwriting described above. For example, supervisors may be reluctant to accept innovative pricing strategies based on big data analytical techniques which may be difficult to understand (and therefore approve).

- In some economies (and for some types of insurance), insurers or intermediaries may need to implement specific requirements when distributing insurance products, such as face-to-face sales, or paper documentation requirements which could impede the ability of insurance companies and intermediaries to distribute insurance products through the internet or smartphone apps.

- Some insurance supervisors require insurance companies to directly undertake core insurance functions such as underwriting or claims settlement which could impede their ability to leverage technologies and innovations available through outsourced service providers.

- In many APEC economies, regulation may impede the ability of insurance companies to offer insurance coverage that makes payment based on any factor other than the amount of losses incurred by the policyholder (i.e., on an indemnity basis) (Insurance Development Forum 2019). For example, most United States state insurance laws reportedly require the indemnity principle which means that insurers offering parametric insurance coverage would face legal compliance risks (Sidhu 2020). Some jurisdictions might also define parametric insurance coverage as a derivative rather than an insurance product which leads to different regulatory requirements, including in some cases restrictions on sales to only qualified investors (Insurance Development Forum 2019). 
Harnessing the benefits of technological developments and innovations in insurance underwriting, exposure management, distribution and claims settlement will require insurance regulators and supervisors to adapt existing regulatory and supervisory frameworks to allow the implementation of new approaches while continuing to ensure that policyholders are sufficiently protected from insurer insolvencies and unfair practices (Box 6.1). In many economies, potential adaptations to the regulatory framework are being examined. In Thailand, the Office of the Insurance Commissioner is reportedly considering the issuance of digital insurance licenses to insurers that wish to distribute insurance products only through digital means (Viriyabusaya 2020).

Some economies have established regulatory sandboxes or innovation hubs that allow insurance companies or intermediaries to test new approaches that might diverge from regulatory or supervisory requirements to assess the potential implications for policyholders. For example, the Monetary Authority of Singapore has established a FinTech Regulatory Sandbox (for all types of financial services) that allows approved applicants to benefit from the relaxation of some legal and regulatory requirements to test new products and innovations within a defined space and duration. Applicants are evaluated against a set of criteria aimed at ensuring that the service to be provided involves a new or emerging technology (or innovative use of an existing technology) and will bring benefits to customers and that risks are well-managed and exit plans in place (MAS 2016). The Insurance Authority of Hong Kong, China has established an Insuretech Sandbox with similar conditions and evaluation criteria (Insurance Authority n.d.). Insurance supervisors in Indonesia and Thailand have also established regulatory sandboxes that allow insurance companies to test new innovations (Meurling 2018; Kietduriyakul, Phongsathaporn, and Triwiboonvanit 2017). The Australian Securities and Investments Commission allows fintech companies providing certain services (including distribution of nonlife insurance to households) a 1-year exemption from financial services licensing requirements while they test their products (ASIC n.d.).

A few economies are taking steps to allow coverage on a parametric basis. For example, in the United Kingdom, parametric insurance solutions are eligible to be included in the Financial Conduct Authority's regulatory sandbox (Clyde \& Co 2018). In the PRC, parametric insurance products can reportedly be offered, although approval is required on a case-bycase basis (Clyde \& Co 2018).

Governments and insurance supervisors should also monitor the impact of improved risk assessment on the availability and affordability of insurance for vulnerable populations as a more granular understanding of risk could lead to unaffordable premiums for those at high-risk. 


\section{Box 6.1: Addressing Prudential and Market Conduct Risks in the Application of Emerging Technologies}

The use of big data analytical techniques can pose particular challenges from both a prudential and market conduct perspective. The value of artificial intelligence techniques, for example, is that they can identify correlations and trends not easily identified by manual processes. If there is an error in the design of the algorithms or if the identified correlations are spurious, the outputs of analyses using artificial intelligence could be wrong. If underwriting or exposure management decisions are being made based on those outputs, prudential risks could arise. ${ }^{a}$ Similar concerns exist for market conduct supervision. Mis-calibrated algorithms could lead to unfair pricing for some policyholders and could make it difficult to explain the reasons for pricing decisions to consumers if the algorithms are not well understood (although high premiums derived using artificial intelligence will likely be difficult to explain even where algorithms are properly calibrated). Artificial intelligence techniques could also potentially lead to higher prices for policyholders with characteristics that, for public policy reasons, are not allowed to be considered in pricing decisions. For example, an algorithm could potentially lead to consistently higher pricing for individuals of a certain race, religion or gendereven if information on those attributes is specifically excluded from the dataset-based on its analysis of another characteristic (i.e., proxy discrimination) (Foggan and Tsai 2020). These risks are also relevant for the use of artificial intelligence in other areas of disaster risk management and emergency response.

Many economies are examining policy options for ensuring that artificial intelligence techniques are implemented in a way that is fair, nondiscriminatory, transparent and builds public trust. ${ }^{b}$ OECD members adopted a set of principles on artificial intelligence in May 2019 aimed at promoting artificial intelligence that is "innovative and trustworthy and that respects human rights and democratic values" (OECD 2019b). In June 2019, the G20 adopted Principles for Responsible Stewardship of Trustworthy Al that draw from the OECD principles (G20 2019). Insurance supervisors in many jurisdictions are also developing approaches to ensuring that the use of artificial intelligence by insurers leads to appropriate outcomes. The European Insurance and Occupational Pensions Authority has established a Consultative Expert Group on Digital Ethics in Insurance to assist in the development of digital responsibility principles in insurance (EIOPA 2019). The United States National Association of Insurance Commissioners' Artificial Intelligence Working Group approved a set of principles to avoid proxy discrimination in the use of artificial intelligence techniques (Gandhi, Kosnoff, and Powell 2020).

a A similar challenge exists for decisions based on complex catastrophe models. As a result, many insurance supervisors have implemented a review process for the use of these models by supervised insurers.

b For example, the United States Office of Management and Budget has released guidance to federal agencies aimed at informing the development of regulatory and nonregulatory approaches for technologies and sectors that are empowered or enabled by artificial intelligence (Office of Management and Budget 2020). The European Commission published a white paper that outlines policy options for achieving a regulatory approach to artificial intelligence that promotes investment in the technology while addressing the risks such as the potential for discrimination and privacy intrusion (European Commission 2020).

Source: Authors.

\section{Building user awareness and trust}

The use of emerging technologies and innovations in informing decisions by households, businesses, and local disaster and emergency management officials will only be effective if there is acceptance and trust in the outputs derived from the application of these technologies:

- The benefits of emerging technologies and innovations for improving decisions on spatial planning, risk reduction investment or emergency response will only be realized if the local officials making those decisions have trust in the conclusions derived through the application of these technologies. 
- Early warning communications based on the application of emerging technologies and innovation to forecasting will only be adhered to if there is trust in the community regarding the accuracy of those forecasts and the assessment of danger to individuals and businesses that the forecasts provide.

- The financial protection offered by indemnity or parametric insurance products underwritten using emerging technologies and innovation and distributed through digital means will only be acquired by individuals and business if there is acceptance of the benefits of that protection, including the capacity of insurers to meet their obligations to policyholders in the event of a disaster.

Building acceptance and trust requires investment by governments and the (re)insurance sector in public information and educational campaigns as well as in developing financial and digital literacy (Box 6.2). In the case of insurance, there may also be a need to build confidence in the capacity of governments and insurance supervisors to oversee the solvency and financial capacity of insurance companies.

Increased public acceptance of some types of emerging technologies and innovations is also critical to building the datasets necessary for applying these technologies. For example, higher levels of trust (including in privacy protection) could increase the willingness of individuals to provide volunteered geographic information through social networks or even through smartphone apps developed for this purpose. Experience in some economies has demonstrated that it can be difficult to build up a large user base. For example, a study on the usage of disaster risk management smartphone apps in India (which is a thriving market for smartphone apps) found that locally developed apps averaged only 1,119 (out of an estimated 300 million smartphone users) (Ghosh 2020).

\section{Box 6.2: Encouraging Technology Adoption}

The adoption of new technologies may require specific encouragement by governments through appropriate governance arrangements and incentives. Governance arrangements within disaster management agencies may discourage risk-taking and/or innovation. A lack of funding for pilot projects to test new approaches using emerging technologies or innovations may impede innovation.

To encourage innovation across disaster risk management policies and activities, innovation could be made a distinct goal. A "Chief Technology Officer" role could be created within disaster risk management agencies with the aim of supporting the adoption of emerging technologies and innovations. The Chief Technology Officer could be supported by an advisory board composed of scientists and academics. As outlined in the 2019 APEC Economic Policy Report, governments can play an important role in encouraging technology adoption by integrating innovation into government operations (APEC 2019).

Funding could be allocated to pilot projects that apply emerging technologies and innovation to key disaster risk management challenges. One approach could be to implement "challenge funds" or competitions open to public, private, and academic sector innovators. For example, in Rio de Janeiro (Brazil), the municipal government has organized a "hackathon" aimed at identifying innovative solution to addressing the city's flood risk challenges (Moloney 2019). 


\section{Opportunities for international cooperation}

There are significant opportunities for APEC economies to learn from each other's experience in integrating emerging technologies and innovations into disaster risk management and financing, including through

- the development of networks and mechanisms to transfer technical skills and knowledge between APEC economies;

- regional cooperation on the development of analytical techniques for risk and impact assessment, including catastrophe models and other types of risk and impact analysis tools;

- sharing of experience on the development of regulatory frameworks that support the availability of data for assessing disaster and climate risks and disaster impacts, including regulatory frameworks related to the commercial use of drones and privacy protection regulation;

- sharing of experience on adapting insurance regulatory frameworks to allow for the integration of emerging technologies and innovation into insurance underwriting, exposure management, distribution and claims settlement, as well as for the authorization of non-indemnity (parametric) insurance coverage while providing sufficient levels of consumer protection; and

- recognition of innovative insurance products where tested under insurance regulatory frameworks in other APEC economies.

In some of these areas, international or regional cooperation initiatives have been established and can be further leveraged to support the integration of emerging technologies and innovation into disaster risk management and financing. For example, the Global Financial Innovation Network, a network of financial sector regulators, recently agreed to pilot a crossborder sandbox that would allow fintech companies to test their innovations in multiple jurisdictions simultaneously (GFIN 2020). Some of the jurisdictions that have established regulatory sandboxes have also established bilateral cooperation agreements that allow them to make referrals on innovative businesses seeking to enter each other's markets (OECD 2017c). A number of APEC economies are participating in a voluntary mechanism that allows certified companies to transfer personal information across borders, which could facilitate the use of data analysis and processing capacity available in other member economies (APEC 2019). 


\section{References}

ACRE Africa. n.d. ACRE Africa, ACRE Africa, https://acreafrica.com/

Adamski, S. 2019. Crowdsourcing Disasters and Social Engagement Multiplied. Federal Emergency Management Agency Blog. 2 August. https://www.fema.gov/blog/2013-08-02/crowdsourcing-disasters-and-social -engagement-multiplied

Alexander, D., R. Grenier, and T. Brooks. 2020. Geospatial Intelligence Revolution in Insurance and Risk Management. Trajectory Magazine. 28 April. https://trajectorymagazine.com/geospatial-intelligence -revolution-in-insurance-and-risk-management/

Altaweel, M. 2020. Cloud-Based Geospatial Analysis. GIS Lounge. 29 January. https://www.gislounge.com/cloud -based-geospatial-analysis/

Amos, J. 2020. Bushfires: Australian Satellite Would Be "Tuned" to Eucalypt Vegetation. BBC News. 3 March. https://www.bbc.com/news/science-environment-51727231

Asian Development Bank (ADB). 2018a. Toward Resilient Kolkata: Introducing India's First Comprehensive City-Level Flood Forecasting and Early Warning System. Manila. https://www.adb.org/sites/default/files/ publication/452576/toward-resilient

-kolkata.pdf

- - . 2018b. Technological Innovation for Agricultural Statistics: Special Supplement to Key Indicators for Asia and the Pacific 2018. Manila : ADB. https://www.adb.org/publications/technological-innovation-agricultural -statistics

-_- 2019a. Asian Development Outlook (ADO) 2019: Strengthening Disaster Resilience. Manila: ADB. https:// www.adb.org/publications/asian-development-outlook-2019-strengthening-disaster-resilience

-_- 2019b. The Enabling Environment for Disaster Risk Financing in Nepal: Country Diagnostics Assessment. Manila. https://www.adb.org/publications/environment-disaster-risk-financing-nepal

- - . 2019c. The Enabling Environment for Disaster Risk Financing in Pakistan: Country Diagnostics Assessment. Manila. https://www.adb.org/publications/pakistan-environment-disaster-risk-financing

- - . 2019d. The Enabling Environment for Disaster Risk Financing in Sri Lanka: Country Diagnostics Assessment. Manila. https://www.adb.org/publications/sri-lanka-environment-disaster-risk-financing 
_-_. 2019e. The Enabling Environment for Disaster Risk Financing in Fiji: Country Diagnostics Assessment. Manila. https://www.adb.org/publications/fiji-environment-disaster-risk-financing

- - . 2020. Assessing the Enabling Environment for Disaster Risk Financing: A Country Diagnostics Tool Kit. Manila: ADB. http://dx.doi.org/10.22617/TCS200190-2

Asia Pacific Economic Cooperation (APEC). 2015. APEC Finance Ministers Process Roadmap / Cebu Action Plan. https://www.apec.org/Meeting -Papers/Sectoral-Ministerial-Meetings/Finance/2015_finance/annexa

- - 2019. 2019 APEC Economic Policy Report. Singapore: APEC.

Australian Securities and Investments Commission (ASIC). n.d. Licensing Exemption for Fintech Testing. http:// download.asic.gov.au/media/4112096/licensing-exemption-for-fintech-testing-infographic.pdf

Beal, J. 2019. State of Al and ML in Insurance. LexisNexis Risk Solutions. https://risk.lexisnexis.com/insights -resources/research/state-of-ai-ml-in-the-insurance-industry

Betterview. n.d. Betterview (Home). https://www.betterview.com/

Blink Parametric. n.d. Product - Blink Climate, Blink Parametric. https://blinkparametric.com/blink-parametric -platform/blink-climate/

Blumenstock, J., N. Eagle and M. Fafchamps. 2016. Airtime Transfers and Mobile Communications: Evidence in the Aftermath of Natural Disasters. Journal of Development Economics. 120 (C). pp. 157-181.

Buchholz, K. 2019. Chart: Commercial Drones are Taking Off. Statista. 28 February. https://www.statista.com/ chart/17201/commecial-drones-projected-growth/

Cape Analytics. n.d. Perils: Wildfire \& Wind. Cape Analytics. https://capeanalytics.com/perils-wildfire-wind/

Carrier Management. 2019. Neptune Flood's Albert: InsurTech Enables Cheaper and More Efficient Flood Coverage. Carrier Management. 11 November. https://www.carriermanagement.com/ news/2019/11/11/200247.htm

Carrigan, D. and J. Spies. 2020. Climate Change Will Heighten Focus on Parametric Insurance in Australia. Clyde \& Co. 3 January. https://www.clydeco.com/en/insurance/2020/01/climate-change-will-heighten-focus-on -parametric-i

CCRIF SPC. n.d. Home, CCRIF SPC. https://www.ccrif.org/

California Department of Insurance (CDI). 2019a. New Data Shows Insurance Is Becoming Harder to Find as a Result of Wildfires. Press release. 20 August. http://www.insurance.ca.gov/0400-news/0100-pressreleases/2019/release063-2019.cfm

- - - 2019b. Wildfire Insurance Crisis Leads Commissioner to Call for First-Ever Statewide Non-Renewal Moratorium. Press release. 5 December. http://www.insurance.ca.gov/0400-news/0100-press -releases/2019/release092-19.cfm 
CEOS. 2015. Satellite Earth Observations in Support of Disaster Risk Reduction, European Space Agency - Earth Observation Graphic Bureau.

CIMA Foundation. n.d. e-DRIFT. http://edrift.cimafoundation.org/edrift/

Cisco. 2018a. Cisco Annual Internet Report (2018-2023) White paper. https://www.cisco.com/c/en/us/solutions/ collateral/executive-perspectives/annual-internet-report/white-paper-c11-741490.html

- - . 2018b. Global Cloud Index Projects Cloud Traffic to Represent 95 Percent of Total Data Center Traffic by 2021. The Network. News release. 5 February. https://newsroom.cisco.com/press-release-content?type=we bcontent\&articleld $=1908858$

Clyde \& Co. 2018. Parametric Insurance: Closing the Protection Gap. https://online.flippingbook.com/ view/281994/

Compta Emerging Business. n.d. Bee2FireDetection. https://www.ceb-solutions.com/products/ bee2firedetection/

Convr. n.d. The Convr Underwriting Platform. https://www.convr.com/platform

Cytora. n.d. Property API, Cytora. https://cytora.com/property/

Dai, S. 2020. China Enlists Al to Speed Up Monitoring and Prediction of Earthquakes. 6 March.

Dave, P. 2020. Google Turns Android Phones Into Earthquake Sensors. Insurance Journal. 12 August. https://www .insurancejournal.com/news/national/2020/08/12/578814.htm

Davis, D. 2019. AI Unleashes the Power of Unstructured Data. CIO. 9 July. https://www.cio.com/article/3406806/ ai-unleashes-the-power-of-unstructured-data.html

de Bruijn, J., H. de Moel, B. Jongman, M. C. de Ruiter, J. Wagemaker, and J. C. J. H. Aerts. 2019. A Global Database of Historic and Real-Time Flood Events Based on Social Media. Scientific Data. 6 (311). http://dx.doi.org/ 10.1038/s41597-019-0326-9

de Smith, M., M. Goodchild and P. Longley. 2020. Geospatial Analysis: A Comprehensive Guide to Principles, Techniques and Software Tools (2020 Update). Drumlin Security. https://spatialanalysisonline.com/

Delos Insurance. n.d. Delos Insurance. Website. https://getdelos.com/

DeStefano, T., R. Kneller, and J. Timmis. 2019. Cloud Computing and Firm Growth. Discussion Papers. University of Nottingham. https://ideas.repec.org/p/not/notgep/2019-09.html

Deutsche Gesellschaft für Internationale Zusammenarbeit (GIZ) and Risk Management Solutions. 2019. Disaster Risk Finance: A Toolkit. GIZ.

Devaraj, A., D. Murthy, and A. Dontula. 2020. Machine-Learning Methods for Identifying Social Media-Based Requests for Urgent Help during Hurricanes. International Journal of Disaster Risk Reduction. 51. pp. 101757, http://dx.doi.org/10.1016/j.ijdrr.2020.101757 
Dillon, A. and L. Rao. 2018. Land Measurement Bias: Comparisons from Global Positioning System, Self-Reports, and Satellite Data. ADB Economics Working Paper Series No. 540. Manila. https://www.adb.org/publications/ land-measurement-bias-gps-satellite-data

Dulebenets, M., J. Pasha, O. F. Abioye, M. Kavoosi, E. E. Ozguven, R. Moses, W. R. Boot, T. Sando. 2019. Exact and Heuristic Solution Algorithms for Efficient Emergency Evacuation in Areas with Vulnerable Populations. International Journal of Disaster Risk Reduction. 39: pp. 101114, http://dx.doi.org/10.1016/j.ijdrr.2019.101114

Duong, J. and R. Levine. 2018. Community Mapping in Viet Nam. Missing Maps. 17 August. https://www. missingmaps.org/blog/2018/08/17/community-mapping-in-vietnam/

European Insurance and Occupational Pensions Authority (EIOPA). 2019. EIOPA Establishes Consultative Expert Group on Digital Ethics in Insurance, European Insurance and Occupational Pensions Authority. EIOPA. 17 September. https://www.eiopa.europa.eu/content/eiopa-establishes-consultative-expert-group -digital-ethics-insurance_en

European Space Agency (ESA). 2020. Second Capacity Building Workshop to the Government of Indonesia's users on EO Products for Disaster Risk Reduction, European Space Agency. News release. 3 February. https://www.eo4sd-drr.eu/news/second-capacity-building-workshop-governmentindonesia\%E2\%80\%99s-users-eo-products-disaster-risk

- - - n.d. EO training \& education - EO Science for Society. Paris. https:/eo4society.esa.int/training-education/

Estrada, M. and A. Ndoma. 2019. The Uses of Unmanned Aerial Vehicles -Uav's- (or Drones) in Social Logistic: Natural Disasters Response and Humanitarian Relief Aid. Procedia Computer Science. 149. pp. 375-383. http://dx.doi.org/10.1016/j.procs.2019.01.151

European Commission. 2020. White Paper: On Artificial Intelligence - A European Approach to Excellence and Trust. European Commission. Brussels. https://ec.europa.eu/info/sites/info/files/commission-white-paper -artificial-intelligence-feb2020_en.pdf

First Insurance Company of Hawaii. n.d. First-Track, First Insurance Company of Hawaii. https://www.ficoh.com/ personal/first-track

FloodFlash. n.d. About - FloodFlash Commercial Flood Insurance. https://floodflash.co/about/

Foggan, L., and K. Tsai. 2020. Insurance - Al and Insurance: What's in That Black Box? Crowell \& Moring's Regulatory Forecast 2020. Crowell \& Moring. 26 February. https://www.crowell.com/NewsEvents/ Regulatory-Forecast/2020/Articles/Insurance-Al-and-Insurance-Whats-in-That-Black-Box

Frasson, R., G. J.-P. Schumann, A. J. Kettner, G. R. Brakenridge, W. F. Krajewski. 2019. Will the Surface Water and Ocean Topography (SWOT) Satellite Mission Observe Floods? Geophysical Research Letters. 46 (17-18). pp. 10435-10445. http://dx.doi.org/10.1029/2019GL084686

Fujitsu Global. 2019. Fujitsu Leverages AI Tech in Joint Project to Contribute to Safe Tsunami Evacuation in Kawasaki. News release. 24 October. https://www.fujitsu.com/global/about/resources/news/press -releases/2019/1024-01.html 
G20. 2019. G20 Ibaraki-Tsukuba Ministerial Meeting on Trade and Digital Economy. G20 Ministerial Statement on Trade and Digital Economy. News release. 10 June. https://www.meti.go.jp/english/ press/2019/0610_003.html

Gandhi, J., S. Kosnoff, and S. Powell. 2020. NAIC's Artificial Intelligence Working Group Adopts Principles for AI. JDSupra. 2 July. https://www.jdsupra.com/legalnews/naic-s-artificial-intelligence-working-40406/

Gartner. 2019. Cloud Adoption: Where Does Your Country Rank? Gartner. 19 August. https://www.gartner.com/ smarterwithgartner/cloud-adoption-where-does-your-country-rank/

Gavi. n.d. Gavi’s Business Model. Gavi. https://www.gavi.org/our-alliance/operating-model/gavis-business-model

Geiß, C., M. Klotz, and H. Taubenböck. 2014. Earth Observation Techniques for Seismic Building Vulnerability Assessment.

Global Facility for Disaster Risk and Recovery (GFDRR). 2018. Machine Learning for Disaster Risk Management. Guidance note. World Bank, Washington, DC. https://www.gfdrr.org/en/publication/machine-learning -disaster-risk-management

Global Financial Innovation Network (GFIN). 2020. Cross-Border Testing: The GFIN Cross-Border Testing Pilot. https://www.thegfin.com/crossborder-testing

Ghosh, S. 2020. Study Finds Limited Outreach of Disaster-Related Mobile Apps in India. Mongabay. 6 January. https://india.mongabay.com/2020/01/study-finds-limited-outreach-of-disaster-related-mobile-apps-in -india/

GlobalData. 2020. United Kingdom Insurance Aggregators 2020. GlobalData, https://www.researchandmarkets. com/reports/5117335/uk-insurance-aggregators-2020 [133]

Green, A. 2020. Deep Data Helps Cities Prepare for Disaster. Financial Times. 29 January. https://www.ft.com/ content/12937096-1b6f-11ea-81f0-0c253907d3e0

Gros, C., M. Bailey. S. Schwager, A. Hassan, R. Zingg, M. MamtazUddin, M. Shahjahan Hasibullslam, S. Lux, C. Jaime, E. C. de Perez. 2019. Household-Level Effects of Providing Forecast-Based Cash in Anticipation of Extreme Weather Events: Quasi-Experimental Evidence from Humanitarian Interventions in the 2017 Floods in Bangladesh. International Journal of Disaster Risk Reduction. 41. pp. 101275. http://dx.doi.org/ 10.1016/j.ijdrr.2019.101275

GSMA. 2019. The State of Mobile Internet Connectivity. GSM Association.

Guan, K., N.T. Hien, Z. Li, and L. K. Nagraj Rao. 2018. Measuring Rice Yield from Space: The Case of Thai Binh Province, Viet Nam. Economics Working Paper Series No. 541. Manila: ADB. https://www.adb.org/ publications/measuring-rice-yield-space-viet-nam

Gupta, A., A. Wein and J. Haveman. 2019. Variability of Business Characteristics Exposed to Building Damages from Earthquakes in the San Francisco Bay Area. Earth and Space Science Open Archive. 29 January. http:// dx.doi.org/10.1002/ESSOAR.10501861.1 
Hallegatte, S., A. Vogt-Schilb, M. Bangalore, J. Rozenberg. 2016. Unbreakable: Building the Resilience of the Poor in the Face of Natural Disasters. Washington, DC: World Bank. http://dx.doi.org/10.1596/978-1-4648-1003-9

Ham, Y., J. Kim, and J. Luo. 2019. Deep Learning for Multi-Year Enso Forecasts. Nature. 573 (7775). pp. 568-572. http://dx.doi.org/10.1038/s41586-019-1559-7

Haritos, C. 2020. Online Warnings When the Threat Is High. National Council for Fire and Emergency Services. 27 February. https://www.afac.com.au/auxiliary/publications/newsletter/article/online-warnings-when-the -threat-is-high

HazardHub. n.d. About HazardHub. https://hazardhub.com/about/

Higgins, L. 2018. Building Maps with Street-Level Imagery for Disaster Risk Reduction and Response. The Mapillary Blog. 15 October. https://blog.mapillary.com/update/2018/10/15/street-level-imagery-for -disaster-risk-reduction-and-response.html

Hippo. n.d. About. Hippo, https://www.hippo.com/about

Holmes, K. 2018. Why Application-Less Placements Make Sense for Commercial Insurance. Carrier Management. 1 May. https://www.carriermanagement.com/features/2018/05/01/177626.htm?bypass=9ced45f02f28303 $8 \mathrm{~b} 2 \mathrm{ff} 2 \mathrm{e} 01 \mathrm{c} 28 \mathrm{aa} 2 \mathrm{~d} 8$

Hugenbusch, D., and T. Neumann. 2016. Cost-Benefit Analysis of Disaster Risk Reduction: A Synthesis for Informed Decision Making. Bonn: Aktion Deutschland Hilft e.V. https://www.aktion-deutschland-hilft.de/fileadmin/ $\mathrm{fm}$-dam/pdf/publikationen/aktion-deutschland-hilft-studie-zur-katastrophenvorsorge-englische-version -english-version.pdf

Insurance Information Institute (III). n.d. Homeowners Insurance Industry Losses and Underwriting Expenses. 2018. iii. https://www.iii.org/table-archive/23319

International Monetary Fund (IMF). 2019. World Economic Outlook, April 2019: Growth Slowdown, Precarious Recovery. Statistical Appendix. Washington, DC. https://www.imf.org/en/Publications/WEO/Issues/2019/ 03/28/world-economic-outlook-april-2019\#Statistical\%20Appendix

Inclusivity Solutions. n.d. Inclusivity Solutions. https://inclusivitysolutions.com/solutions/

Insurance Authority. n.d. Insurtech Corner, Insurance Authority. https://www.ia.org.hk/en/aboutus/insurtech _corner.html\#1

Insurance Development Forum (IDF). 2019, How Technology Can Help Bridge the Protection Gap. IDF paper. https://www.insdevforum.org/idf-paper-how-technology-can-help-bridge-protection-gap

Insurance Journal. 2019. New Hurricane Response Tools from Munich Re Aim to Improve Claims Experience. 7 August. https://www.insurancejournal.com/news/national/2019/08/07/535165.htm

- - - 2020a. Insurtech MGA Delos, Canopius to Offer Wildfire Protection Coverage in California. 29 June. https://www.insurancejournal.com/news/west/2020/06/29/573711.htm 
- - - 2020b. Swiss Re Corporate Solutions Launches Parametric Product for Hail-Prone States. 29 May. https://www.insurancejournal.com/news/national/2020/05/29/570500.htm

- - - 2020c. Swiss Re's iptiQ and IKEA Partner to Offer Home Insurance. 18 February. https://www.insurance journal.com/news/international/2020/02/18/558656.htm

Insurdata. n.d. Why Insurdata. https://www.insurdata.io/usp/

InsuResilience. 2018. Annual Report 2018: Working Toward a Climate-Resilient Future. Deutsche Gesellschaft für Internationale Zusammenarbeit (GIZ).

Intel. 2020. 2020 CES: How Intel AI Helps the Red Cross Generate Open Source Maps for Disaster Relief. Intel Newsroom. 8 January. https://newsroom.intel.com/news/how-intel-ai-helps-red-cross-generate-open -source-maps-disaster-relief/\#gs.qrws7c.a87ffc

International Telecommunications Union (ITU). 2018. Measuring the Information: Society Report - Vol. 1. ITU Publications.

Intergovernmental Panel on Climate Change (IPCC). 2012. Managing the Risks of Extreme Events and Disasters to Advance Climate Change Adaptation. Cambridge: Cambridge University Press.

iptiQ. n.d., About us - iptiQ, iptiQ, https://www.iptiq.com/gb/about-us/

International Rescue Committee (IRC). 2016. Making Electronic Payments Work for Humanitarian Response. Report. https://www.rescue.org/report/making-electronic-payments-work-humanitarian-response

I-REACT. n.d., I-REACT Brochure, Improving Resilience to Emergencies through Advanced Cyber Technologies. http://www.project.i-react.eu/wp-content/uploads/2017/05/brochure-i-react-DEF.pdf

Istuk, I., O. Ardic, and J. Allen. 2020. Will Smart Contracts Usher in a New Wave of Financial Inclusion? World Bank Blogs. 8 July. https://blogs.worldbank.org/psd/will-smart-contracts-usher-new-wave-financial -inclusion

Iwakura, T., S. Okajima, N. Igata, K. Takeda, Y. Yamakage, N. Morita. 2018. Detecting Heavy Rain Disaster from Social and Physical Sensors. Proceedings of the 27th International Conference on Computational Linguistics: System Demonstrations. Association for Computational Linguistics. ACL Anthology. https:// www.aclweb.org/anthology/C18-2014

Jumpstart. 2018. Example Maps: Payment Eligibility Zones. Jumpstart. 1 November. https://blog. jumpstartrecovery.com/earthquake-insurance-payout-zone/

Jupiter. n.d. Jupiter Services: Dynamic Technology Delivers Precise Asset-Level Predictions. https://jupiterintel .com/services/

Kaesler, S., J. Lorenz, and F. Schollmeier. 2018. Insurance Aggregators in Europe and Their Impact on Traditional Insurers. McKinsey \& Company. 10 December. https://www.mckinsey.com/industries/financial-services/our -insights/friends-or-foes-the-rise-of-european-aggregators-and-their-impact-on-traditional-insurers 
Kayitakire, F., M. Sharma, N. Kiesslich, and M. Nobakht. 2020. How EO Data Is Deepening Our Knowledge of Flood Risk and Water Resource Management. European Space Agency. http://eo4sd -climate.gmv.com/ content/webinar-series-1-module-4

Khodaverdizahraee, N., H. Rastiveis and A. Jouybari. 2020. Segment-by-Segment Comparison Technique for Earthquake-Induced Building Damage Map Generation Using Satellite Imagery. International Journal of Disaster Risk Reduction. 46: pp. 101505. http://dx.doi.org/10.1016/j.ijdrr.2020.101505

Kietduriyakul, K., K. Phongsathaporn, and M. Triwiboonvanit. 2017. Thailand: The Fintech Wave and Regulatory Response. Baker McKenzie. 3 August. https://financialinstitutions.bakermckenzie.com/2017/08/03/ thailand-the-fintech-wave-and-regulatory-response/

Kirk, E. 2019. MetLife Prepares for the Storms of Tomorrow with IMGING. Loveland Innovations. 23 September. https://www.lovelandinnovations.com/blog/metlife-imging/

Kong, Q., R. M. Allen, L. Schreier, and Y-W. Kwon. 2016. Earth Sciences: MyShake: A Smartphone Seismic Network for Earthquake Early Warning and Beyond. Science Advances. 2 (2). pp. e1501055, http://dx.doi.org/ $10.1126 /$ sciadv. 1501055

Le Cozannet, G., M. Kervyn, S. Russo, C. Ifejika Speranza, P. Ferrier, M. Foumelis, T. Lopez, and H. Modaressi. 2020. Space-Based Earth Observations for Disaster Risk Management. Survey in Geophysics. http://dx.doi. org/10.1007/s10712-020-09586-5

Lee, J., D. Grosz, S. Zeng, B. Uzkent, M. Burke, D. Lobell, S. Ermon. 2020. Predicting Livelihood Indicators from Crowdsourced Street Level Images. http://arxiv.org/abs/2006.08661

Lemonade. n.d. Lemonade Contents \& Personal Liability Insurance. https:/www.lemonade.com/de/en

Lloyd's. 2012. Global Underinsurance Report. London: Lloyd's. https://www.lloyds.com/news-and-risk-insight/risk -reports/library/understanding-risk/global-underinsurance-report

- - 2018. A World at Risk: Closing the Insurance Gap. London: Lloyd's.

Monetary Authority of Singapore. (MAS). 2016. FinTech Regulatory Sandbox Guidelines. MAS, Singapore. https://www.mas.gov.sg/-/media/MAS/Smart-Financial-Centre/Sandbox/FinTech-Regulatory-Sandbox -Guidelines-19Feb2018.pdf?la=en\&hash=B1D36C055AA641F580058339009448CC19A014F7

Matgen, P., V. Freeman, W. Wagner, P. Zeil, S. Martinis, N. McCormick. 2020. Feasibility Assessment of an Automated, Global, Satellite-Based Flood-Monitoring Product for the Copernicus Emergency Management Service. Publications Office of the European Union. http://dx.doi.org/10.2760/653891

Mcintosh, C. and C. Mansini. 2018. The Use of Financial Technology in the Agriculture Sector. Tokyo: Asian Development Bank Institute. https://www.adb.org/publications/use-financial-technology-agriculture -sector

Meagher, K. 2019. Leveraging Smart Home and loT for New Insurance Business Models. Parks Associates White Paper. https://www.the-digital-insurer.com/wp-content/uploads/2019/02/1437-ParksAssoc-LeveragingSm artHomeforlnsuranceBusinessModels.pdf 
Measure and American Red Cross. 2015. Drones for Disaster Response and Relief Operations. Paper. https:// www.issuelab.org/resources/21683/21683.pdf

Meiping, G. 2020. How Does Advanced Technology Save Lives in China’s Flood-Prone Areas? China Global Television Network. 13 July. https://news.cgtn.com/news/2020-07-13/How-does-advanced-technology -save-lives-in-China-s-flood-prone-areas--S5AGdp9le4/index.html

Melecky, M. and C. Raddatz. 2011. How Do Governments Respond after Catastrophes? Natural-Disaster Shocks and the Fiscal Stance. Policy Research Working Paper, No. 5564. Washington, DC: World Bank. https:// openknowledge.worldbank.org/bitstream/handle/10986/3331/WPS5564.pdf? sequence=1\&isAllowed=y

Meurling, N. 2018. Indonesia - OJK's Fintech Sandbox. Conventus Law. https://www.conventuslaw.com/report/ indonesia-ojks-fintech-sandbox/

Miyamoto International and United States Agency for International Development (USAID). 2019. Haiti: Response Preparedness and Building Resilience. https://www.preventionweb.net/files/submissions/69792 _usaidofdasuccessstorydisasterresponseapplaunchesinhaiti.pdf

Moloney, A. 2019. Disaster Hacks: South American Cities Harness Tech and Nature to Tackle Floods. Thompson Reuters Foundation News. 22 November. https://news.trust.org/item/20191122145839-x2cp1/

Moore, F., and N. Obradovich. 2020. Using Remarkability to Define Coastal Flooding Thresholds. Nature Communications. 11/1. pp. 1-8, http://dx.doi.org/10.1038/s41467-019-13935-3

Moya, L., E. Mas and S. Koshimura. 2020. Learning from the 2018 Western Japan Heavy Rains to Detect Floods during the 2019 Hagibis Typhoon. Remote Sensing. 12 (14): pp. 2244. http://dx.doi.org/10.3390/rs12142244

National Aeronautic and Space Administration (NASA). 2019. Introductory Webinar: Earth Observations for Disaster Risk Assessment \& Resilience. Washington, DC. https://arset.gsfc.nasa.gov/disasters/webinars/19 -DRA?utm_source=social\&utm_medium=PDC\&utm_campaign=DRA

NASA Global Precipitation Measurement Mission. 2018. Modeling Landslide Threats in Near Realtime. NASA. Washington, DC. https://gpm.nasa.gov/applications/disasters/modeling-landslide-threats-near-realtime

Neptune Flood. n.d. Flood Insurance Coverage - Neptune Flood, Neptune Flood. https://neptuneflood.com/ flood-insurance-coverage/

Newman, J. P., H. R. Maier, G. Riddell, and A. C. Zecchin. 2017. Review of Literature on Decision Support Systems for Natural Hazard Risk Reduction: Current Status and Future Research Directions. Environmental Modelling \& Software. 96: pp. 378-409. http://dx.doi.org/10.1016/j.envsoft.2017.06.042

National Institute of Building Societies (NIBS). 2019. Natural Hazard Mitigation Saves: 2019 Report. Washington, DC. https://www.nibs.org/page/mitigationsaves

Nobakht, M. 2020. EO4SD CR Rainfall Explorer. European Space Agency. http://eo4sd-climate.gmv.com/ content/webinar-series-1-module-4 
Organisation for Economic Co-operation and Development (OECD). 2014. Boosting Resilience through Innovative Risk Governance. Paris: OECD Publishing.

- - . 2016. OECD Insurance Statistics. Database. https://stats.oecd.org/Index.aspx? DatasetCode=INSIND

- - . 2016. Financial Management of Flood Risk. Paris: OECD Publishing. https://www.oecd.org/daf/fin/ insurance/OECD-Financial-Management-of-Flood-Risk.pdf

- - 2017a. OECD Recommendation on Disaster Risk Financing Strategies. https://www.oecd.org/finance/ oecd-recommendation-disaster-risk-financing-strategies.htm

- - 2017b. Development Co-operation Report 2017: Data for Development. Paris: OECD Publishing. https:// dx.doi.org/10.1787/dcr-2017-en

- - . 2017c. Technology and Innovation in the Insurance Sector. Paris: OECD Publishing. https://www.oecd.org/ pensions/Technology-and-innovation-in-the-insurance-sector.pdf

- - . 2017d. Embracing Innovation in Government - Global Trends. Paris: OECD Publishing.

- - 2018a. Assessing the Real Cost of Disasters: The Need for Better Evidence, OECD Reviews of Risk Management Policies. Paris: OECD Publishing. https://dx.doi.org/10.1787/9789264298798-en

- - - 2018b. The Contribution of Reinsurance Markets to Managing Catastrophe Risk. http://www.oecd.org/ finance/the-contribution-of-reinsurance-markets-to-managing-catastrophe-risk.pdf

- - . 2018c. Financial Management of Earthquake Risk. Paris: OECD Publishing. https://www.oecd.org/daf/fin/ insurance/financial-management-of-earthquake-risk.htm

- - 2019a. Vectors of Digital Transformation. OECD Digital Economy Papers. 273. https://doi.org/10.1787/ 5ade2bba-en

-_- 2019b. OECD Principles on Artificial Intelligence. OECD. https://www.oecd.org/going-digital/ai/ principles/

- - . 2020a. Regulatory and Supervisory Framework for Insurance Intermediation. https://www.oecd.org/daf/ fin/insurance/Regulatory-and-Supervisory-Framework-for-Insurance-Intermediation.pdf

-_- 2020b. The Impact of Big Data and Artificial Intelligence (AI) in the Insurance Sector. Paris: OECD Publishing.

- - 2020c. OECD Reviews of Public Health: Korea. Paris: OECD Publishing.

OECD/FAO. 2016. Agriculture in Sub-Saharan Africa: Prospects and Challenges for the Next Decade. Paris: OECD Publishing.

OECD/World Bank. 2019. Fiscal Resilience to Natural Disasters: Lessons from Country Experiences. Paris: OECD Publishing. https://dx.doi.org/10.1787/27a4198a-en 
Office of Management and Budget. 2020. Request for Comments on a Draft Memorandum to the Heads of Executive Departments and Agencies. Guidance for Regulation of Artificial Intelligence Applications. Federal Register notice. 13 January. https://www.federalregister.gov/documents/2020/01/13/2020-00261/ request-for-comments-on-a-draft-memorandum-to-the-heads-of-executive-departments-and-agencies

Ogie, R., R.J. Clarke, H. Forehead, P. Perez. 2019. Crowdsourced Social Media Data for Disaster Management: Lessons from the PetaJakarta.org Project. Computers, Environment and Urban Systems. 73: pp. 108-117, http://dx.doi.org/10.1016/j.compenvurbsys.2018.09.002

OPT/NET. 2020. Emergency Management White Paper - Flood Mapping. https://optoss.nl/OPT-NET-EMS -WP.pdf

O'Shea, T. 2019. Monitoring Wildfire Risk Using Space and AI. Planet. 19 August. https://www.planet.com/pulse/ monitoring-wildfire-risk-using-space-and-ai

Pandey, D. 2020. How Blockchain and Smart Contracts Will Disrupt Insurance. PropertyCasualty360. 24 January. https://www.propertycasualty360.com/2020/01/24/how-blockchain-and-smart-contracts-will-disrupt -insurance/

Park, M. 2019. How Drones Are Accelerating Digital Transformation in the Insurance Industry. Claims Journal. 2 October. https://www.claimsjournal.com/news/national/2019/10/02/293363.htm?utm_content=cyber security-awareness-month\&utm_campaign=insuring-cyber\&utm_source=insurancejournal\&utm _medium=newsletter

Paunan, J. 2020. Copernicus' Eye in the Sky Brings Disaster Management to a Whole New Level. Philippine Information Agency. 10 February. https://pia.gov.ph/news/articles/1034309

Perera, D., O. Seidou, J. Agnihotri, and H. Mehmood. 2020. Challenges and Technical Advances in Flood Early Warning Systems (FEWSs). In Flood Impact Mitigation and Resilience Enhancement. IntechOpen https:// www.researchgate.net/publication/342424935_Challenges_and_Technical_Advances_in_Flood_Early _Warning_Systems_FEWSs

Poran, T. 2020. Matterport Disrupts Insurance Claims and Restoration with Artificial Intelligence Powered Reality Capture. Matterport. 28 June. https://matterport.com/blog/matterport-disrupts-insurance-claims -restoration-artificial-intelligence-powered-reality

Porter, J. 2020. Zipline's Drones Are Delivering Medical Supplies and PPE in North Carolina. The Verge. 27 May. https://www.theverge.com/2020/5/27/21270351/zipline-drones-novant-health-medical-center-hospital -supplies-ppe

Previsico. n.d. FloodMap Live Technology. https://previsico.com/about/floodmap-live/

Property Drone Consortium. 2018. Property Drone Consortium (PDC) Obtains FAA Waiver Permitting Nighttime Flights. Property Drone Consortium. 16 March. https://www.roofingcontractor.com/articles/92761 -property-drone-consortium-pdc-obtains-faa-waiver-permitting-nighttime-flights

Reinsel, D., J. Gantz, and J. Rydning. 2018. Data Age 2025: The Digitization of the World From Edge to Core. IDC White Paper. https://www.seagate.com/files/www-content/our-story/trends/files/idc-seagate-dataage -whitepaper.pdf 
Reinsurance News. 2017. Swiss Re and Ping An Partner on Mobile Parametric Insurance for Chinese Typhoon Risk. Reinsurance News. 7 July. https://www.reinsurancene.ws/swiss-re-ping-partner-mobile-parametric -insurance-chinese-typhoon-risk/

Ritchie, H., and M. Roser. 2018. Our World in Data. https://ourworldindata.org/urbanization

Rogers, D., and V. Tsirkunov. 2010. Costs and Benefits of Early Warning Systems. Report. United Nations International Strategy for Disaster Reduction and World Bank. https:/www.preventionweb.net/english/ hyogo/gar/2011/en/bgdocs/Rogers_\&_Tsirkunov_2011.pdf

Roost Home Telematics. n.d. Roost Smart Sensors, Roost Home Telematics. https://www.getroost.com/sensors/

Rotairo, L., A. C. Durante, P. Lapitan, L. N. Rao. 2019. Use of Remote Sensing to Estimate Paddy Area and Production: A Handbook. Manila: Asian Development Bank. http://dx.doi.org/10.22617/TIM190098-3

Russon, M. 2018. Drones to the Rescue! BBC News. 1 May. https://www.bbc.com/news/business-43906846

Sams, J. 2020. Not All Homes in Wildfire Zones Are Uninsurable. Here's How Insurers Can Tell. Insurance Journal. 22 May. https://www.insurancejournal.com/news/national/2020/05/22/569684.htm

Schempp, T., H. Zhang, A. Schmidt, M. Hong, R. Akerkar. 2019. A Framework to Integrate Social Media and Authoritative Data for Disaster Relief Detection and Distribution Optimization. International Journal of Disaster Risk Reduction. 39: pp. 101143. http://dx.doi.org/10.1016/j.ijdrr.2019.101143

Schleifstein, M. 2019. How To Better Explain Hurricane Threats? Barry Showed "Good" and "Bad" of Storm Risk Assessment. NOLA.com. 25 August. https://www.nola.com/news/environment/article_afOfe5a4-bd45 -11e9-96ae-93927ddace36.html

Seto, J. 2018. Using Al and loT for Disaster Management. Microsoft Azure. 29 November. https://azure.microsoft .com/en-us/blog/using-ai-and-iot-for-disaster-management/

Sheng, C., D. Kottmann, K. Liu, K. Prestinari, X. Jiang, W. Chen, X. Li. 2017. Technology-Driven Value Generation in Insurance. Oliver Wyman. https://www.oliverwyman.com/our-expertise/insights/2017/jun/technology -driven-value-generation-in-insurance.html

Shuang, F. 2020. Cutting-Edge Technologies Make Flood Prevention Smarter. ECNS. 15 July. http://www.ecns.cn/ news/2020-07-15/detail-ifzyahzt5332675.shtml

Sidhu, V. 2020. Parametric Insurance Key in Meeting Climate Risks for Low Income Individuals and Households in US. Clyde \& Co. 6 February. https://www.clydeco.com/en/insurance/2020/02/parametric-insurance-key -in-meeting-climate-risks\#page $=1$

Sima, R. 2020. Combining Al and Analog Forecasting to Predict Extreme Weather. Eos. 4 March. http://dx.doi.org/ $10.1029 / 2020$ eo140896

Srikanth, R. 2019. How Technology Can Help India Cope with Natural Disasters. Express Computer. 18 November. https://www.expresscomputer.in/egov-watch/how-technology-can-help-india-cope-with-natural -disasters/43603/ 
Standard \& Poor's. 2015. The Heat Is On: How Climate Change Can Impact Sovereign Ratings. Standard \& Poor's Rating Service report. https://www.spglobal.com/ratings/en/research/articles/151125-the-heat-is-on-howclimate-change-can-impact-sovereign-ratings-9425836

Statista. 2019. Annual Number of Mobile App Downloads Worldwide 2016 to 2019. Statista. 17 January. https:// www.statista.com/statistics/271644/worldwide-free-and-paid-mobile-app-store-downloads/

- - - 2020a. Number of Social Media Users Worldwide 2017 to 2025. Statista. 15 July. https://www.statista .com/statistics/278414/number-of-worldwide-social-network-users/

- - - 2020b. Share of Adults Who Use Social Media as a Source of News in Selected Countries Worldwide as of February 2020. Statista. 23 June. https://www.statista.com/statistics/718019/social-media-news-source/

StormPeace. n.d. StormPeace Hurricane Insurance. https://stormpeace.com/

Sukhwani, V., and R. Shaw. 2020. Operationalizing Crowdsourcing through Mobile Applications for Disaster Management in India. Progress in Disaster Science. 5: pp. 100052. http://dx.doi.org/10.1016/j.pdisas.2019 .100052

Sullivan, B. 2019. Artificial Intelligence Helps to Contain Wildfires, Predict Wild Weather. Insurance Journal. 5 August. https://www.insurancejournal.com/news/international/2019/08/05/534839.htm?utm_content =embracing-artificial-intelligence\&utm_campaign=cyber\&utm_source=insurancejournal\&utm_medium =newsletter\#

Suresh, V. 2020. Almost Real-Time Flood Prediction Tool May Boost Emergency Response during Hurricanes. Texas A\&M University Engineering. 28 February. https://Engineering.tamu.edu/news/2020/02/almost-real -time-flood-prediction-tool-may-boost-emergency-response-during-hurricanes.html? -ga $=2.19905980 .501207707 .1583225458-715816615.1583225458$

Surminski, S. and Vivid Economics. 2018. Study on the Assessment of Tools to Support Climate and Disaster Risk Insurance. KFW Development Bank.

Swiderek, D. and J. Wipf. 2015. Aiding the Disaster Recovery Process: The Effectiveness of Microinsurance Service Providers' Response to Typhoon Haiyan. Luxembourg: Microinsurance Network.

Swiss Re. 2018. Swiss Re sigma - Natural Catastrophes and Man-Made Disasters (database).

- - - 2019. Successful Kenya Livestock Insurance Program Scheme Scales Up. Newsletter. https://www .swissre.com/our-business/public-sector-solutions/thought-leadership/successful-kenya-livestock -insurance-program-scheme.html

Tanner, T., E. Lovell, E. Wilkinson, F. Ghesquiere, R. Reid, and S. Rajput. 2015. Why All Development Finance Should Be Risk-Informed. Overseas Development Institute (ODI) and Global Facility for Disaster Reduction and Recovery. https://www.odi.org/sites/odi.org.uk/files/odi-assets/publications-opinion-files/ 9730.pdf

Tatham, P., and S. Pettit. 2010. Transforming Humanitarian Logistics: The Journey to Supply Network Management. International Journal of Physical Distribution \& Logistics Management. 40 (8/9): pp. 609-622. 
Tenevia. n.d. A Network of Cameras to Monitor Floods. Tenevia. Case story. https:/www.tenevia.com/en/case -study/camera-network-to-monitor-floods/

Tractable. n.d. Disasters. https://tractable.ai/products/disasters

Tremaine, K., and K. Tuberson. 2017. How the Internet of Things Can Prepare Cities for Natural Disasters. Harvard Business Review. 1 December. https://hbr.org/2017/12/how-the-internet-of-things-can-prepare-cities-for -natural-disasters

United Nations Office for Disaster Risk Reduction (UNDRR). 2017. Terminology on Disaster Risk Reduction. https://www.unisdr.org/we/inform/terminology

UNDRR and UNESCO-IOC. 2019. Limitations and Challenges of Early Warning Systems: A Case Study of the 2018 Palu-Donggala Tsunami. UNDRR, Intergovernmental Oceanographic Commission of United Nations Educational, Scientific and Cultural Organization. https://www.preventionweb.net/publications/view/68152

UN Economic and Social Commission for Asia and the Pacific (UNESCAP). 2018. Disaster Risk Financing: Opportunities for Regional Cooperation in Asia and the Pacific. https:/www.unescap.org/resources/ disaster-risk-financing-opportunities-regional-cooperation-asia-and-pacific

—- - 2019. Asia-Pacific Disaster Report. New York: United Nations Publications.

United Nations, Department of Economic and Social Affairs. 2018. World Urbanization Prospects: 2018. https:// population.un.org/wup/Download/

United Nations Conference on Trade and Development (UNCTAD). 2019. Data Protection and Privacy Legislation Worldwide. https://unctad.org/en/Pages/DTL/STI_and_ICTs/ICT4D-Legislation/eCom-DataProtection-Laws.aspx

Université Catholique de Louvain, C. 2019. EM-DAT: The Emergency Events Database. https://www.emdat.be/

United States Geological Survey (USGS). n.d. Can You Predict Earthquakes? https://www.usgs.gov/faqs/can-you -predict-earthquakes?qt-news_science_products=0\#qt-news_science_products

Viriyabusaya, S. 2020. Thailand: OIC Considers Granting Insurance Digital Licenses. Baker McKenzie. 7 February. https://www.bakermckenzie.com/en/insight/publications/2020/02/oic-considers-granting-insurance -digital-licenses

Von Peter, G., S. Von Dahlen, and S. Saxena. 2012. Unmitigated Disasters? New Evidence on the Macroeconomic Cost of Natural Catastrophes. BIS Working Papers, No. 394. Bank for International Settlements. https://www .bis.org/publ/work394.pdf

Vorhies, F. 2012. The Economics of Investing in Disaster Risk Reduction. United Nations International Strategy for Disaster Reduction. Working paper. http://www.preventionweb.net/files/32357_drreconomicsworking paperfinal3.pdf 
Wadland, E. 2020. Information Is Power: Women Need Equal Access to ICTs for Disaster Resilience. Emergency Telecommunications Cluster. ETC. 9 March. https://www.etcluster.org/blog/information-power-women -need-equal-access-icts-disaster-resilience

World Bank. 2017. Unbreakable: Building the Resilience of the Poor in the Face of Natural Disasters. Washington, DC: World Bank Publications.

-—-. 2018. GDP (current US\$), https://data.worldbank.org/indicator/ny.gdp.mktp.cd

- - . 2020a. Chapter 3: What Happens to Productivity During Major Adverse Events? In A. Dieppe. ed. Global Productivity: Trends, Drivers, and Policies. Washington, DC: World Bank. https://www.worldbank.org/en/ research/publication/global-productivity

- - - 2020b. World Bank Country and Lending Groups, World Bank, https://datahelpdesk.worldbank.org/ knowledgebase/articles/906519-world-bank-country-and-lending-groups

Yeh, C., A. Perez, A. Driscoll, G. Azzari, Z. Tang, D. Lobell, S. Ermon, and M. Burke 2020. Using Publicly Available Satellite Imagery and Deep Learning to Understand Economic Well-Being in Africa. Nature Communications. 11/1: pp. 1-11, http://dx.doi.org/10.1038/s41467-020-16185-w

Zesty.ai. n.d. Property Insights, Zesty.ai, https://www.zesty.ai/property-insights

Zhang, T., S. Biswal and Y. Wang. 2019. SHMnet: Condition Assessment of Bolted Connection with Beyond Human-Level Performance. Structural Health Monitoring. 19 (4): pp. 147592171988123. http://dx.doi.org/ $10.1177 / 1475921719881237$ 


\title{
Leveraging Technology and Innovation for Disaster Risk Management and Financing
}

Emerging technologies and innovations are contributing to a more comprehensive, accurate, and timely assessment of disaster risk and impacts - and therefore to more effective spatial planning, risk reduction investment and preparedness, and, in most cases, more inclusive risk transfer arrangements. This report proposes strategic approaches to leveraging and integrating these technologies and innovations into effective disaster risk management and financing. It aims to support preparedness and response to increasing disaster and climate risks and to help enhance the financial resilience of economies around the world.

\section{About the Asian Development Bank}

ADB is committed to achieving a prosperous, inclusive, resilient, and sustainable Asia and the Pacific, while sustaining its efforts to eradicate extreme poverty. Established in 1966, it is owned by 68 members -49 from the region. Its main instruments for helping its developing member countries are policy dialogue, loans, equity investments, guarantees, grants, and technical assistance.

\section{About the Organisation for Economic Co-operation and Development}

OECD is an international organization in which governments work together to find solutions to common challenges, develop global standards, share experiences and identify best practices to promote better policies for better lives. Our goal is to shape policies that foster prosperity, equality, opportunity and well-being for all. The OECD brings together Member countries and partners that collaborate closely on key global issues at national, regional and local level. Through our standards and initiatives, our work helps drive and anchor reform in more than 100 economies around the world, building on our collective wisdom and shared values.

$\mathrm{ADB}$

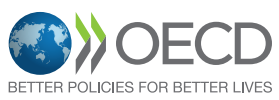

